\title{
ARTICLE OPEN \\ B cell development is critically dependent on NFATc1 activity
}

\author{
Sabrina Giampaolo', Gabriela Wójcik², Stefan Klein-Hessling ${ }^{1,3}$, Edgar Serfling ${ }^{1,3}$ and Amiya K. Patra ${ }^{2}$
}

B cell development in bone marrow is a precisely regulated complex process. Through successive stages of differentiation, which are regulated by a multitude of signaling pathways and an array of lineage-specific transcription factors, the common lymphoid progenitors ultimately give rise to mature B cells. Similar to early thymocyte development in the thymus, early B cell development in bone marrow is critically dependent on IL-7 signaling. During this IL-7-dependent stage of differentiation, several transcription factors, such as E2A, EBF1, and Pax5, among others, play indispensable roles in B lineage specification and maintenance. Although recent studies have implicated several other transcription factors in B cell development, the role of NFATc1 in early B cell developmental stages is not known. Here, using multiple gene-manipulated mouse models and applying various experimental methods, we show that NFATc1 activity is vital for early B cell differentiation. Lack of NFATc1 activity in pro-B cells suppresses EBF1 expression, impairs immunoglobulin gene rearrangement, and thereby preBCR formation, resulting in defective $B$ cell development. Overall, deficiency in NFATC1 activity arrested the pro-B cell transition to the pre-B cell stage, leading to severe B cell lymphopenia. Our findings suggest that, along with other transcription factors, NFATC1 is a critical component of the signaling mechanism that facilitates early B cell differentiation.

Keywords: Differentiation; EBF1; NFATc1; Pro-B; Pre-B

Cellular \& Molecular Immunology (2019) 16:508-520; https://doi.org/10.1038/s41423-018-0052-9

\section{INTRODUCTION}

$B$ cell development in bone marrow (BM) follows a series of differentiation stages through which hematopoietic stem cell (HSC)-derived common lymphoid progenitor (CLP) cells give rise to mature B lymphocytes. Similar to early $T$ cell development in the thymus, early B cell development in BM is also critically dependent on interleukin-7 (IL-7) signaling. ${ }^{1-5}$ Upon IL-7 signaling,

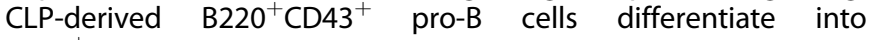
$\mathrm{B} 22 \mathrm{O}^{+} \mathrm{CD}^{-} 3^{-}$pre-B cells, which subsequently differentiate into

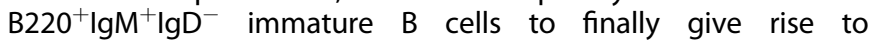

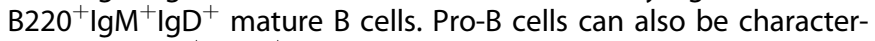
ized as $B 220^{+} I L-7 R^{+}$because they respond to $\mathrm{IL}-7$ signals or $\mathrm{B}_{22} \mathrm{C}^{+} \mathrm{CD} 19^{+} \mathrm{IgM}^{-} \mathrm{C}-\mathrm{Kit}^{+}$cells because they express stem cell factor receptor (c-Kit). Similarly, pre-B cells are otherwise characterized as $B 220^{+} I L-7 R^{-}$because these cells are independent of IL-7 signaling or $\mathrm{B} 220^{+} \mathrm{CD} 19^{+} \mathrm{IgM}^{-} \mathrm{CD} 25^{+}$because they express the IL-2 receptor alpha chain (CD25). During the pro- to pre-B cell transition, developing $B$ cells rearrange their immunoglobulin (Ig) heavy and light chains, which are essential for the formation of the pre-B cell receptor ( $\mathrm{pBCR}$ ). PreBCR signaling imparts independence from IL-7 signaling and is critical for further differentiation to later developmental stages. ${ }^{6,7}$

Apart from IL-7 signaling, a host of lineage-specific transcription factors (TF) have been implicated in the regulation of early $B$ cell differentiation in BM. Prominent among these TFs are the etsfamily TF PU.1, Ikaros, zinc finger TF Bcl11a, helix-loop-helix TF E2A, EBF1 (early B cell factor 1 ), and paired box TF Pax5., ${ }^{8,9}$ Both $E 2 A$ and EBF1 have been reported to regulate $B$ lineage specification and commitment, and Pax5 activity is vital for B lineage maintenance. ${ }^{10-15}$ Genetic ablation of these TFs has revealed serious abnormalities in $\mathrm{B}$ cell development, leading to severe B cell lymphopenia.'

EBF1 activity has been suggested to influence several aspects of early $B$ cell differentiation. ${ }^{16,17}$ EBF1 activity has been shown to regulate Pax5, Pou2af1 (BOB-1/OBF1), and Foxo1 activity during $B$ cell development. ${ }^{15,18-21}$ The master regulatory function of EBF1 in $B$ lineage specification and commitment was evident from the analysis of $E b f 1^{-1-}$ mice, in which development was blocked at the pro-B cell stage. ${ }^{12}$ EBF1 in association with E2A, Runx1, and other TFs regulates a number of $B$ lineage-specifying genes that are involved in early B cell survival, proliferation, and Ig gene locus accessibility and rearrangement. ${ }^{16,22,23}$ Although the functional aspects of EBF1 in $B$ cell development have been extensively studied, the mechanism that induces Ebf1 expression is less well understood. IL-7 signaling has been shown to regulate Ebf1 expression in pro-B cells. $^{24}$ Additionally, E2A and FOXO1 appear to regulate Ebf1 expression. ${ }^{25-27}$ However, a clear picture of the regulation of Ebf1 during early B cell development has yet to emerge.

Nuclear factor of activated T cell (NFAT) family TFs play important roles in the development and function of many hematopoietic cell lineages. ${ }^{28-30}$ Among five family members (NFATC1, NFATC2, NFATc3, NFATc4, and NFAT5), NFATc1, NFATc2, and NFATC3 are predominantly active in lymphocytes, where they regulate processes as diverse as cell survival, proliferation, cytokine gene expression, various $\mathrm{T}$ helper cell differentiation, apoptosis, and immune effector function. ${ }^{31,32}$ In T or B cells, cell

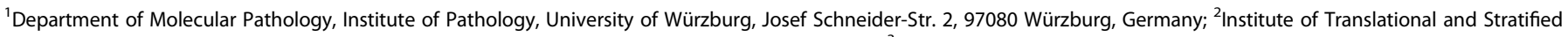

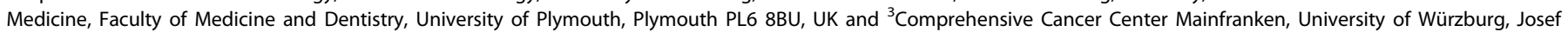
Schneider-Str. 6, 97080 Würzburg, Germany

Correspondence: Amiya K. Patra (amiya.patra@plymouth.ac.uk)

Received: 26 December 2017 Accepted: 23 May 2018

Published online: 15 June 2018 
surface $T$ cell receptor (TCR) or BCR ligation induces increased calcium $\left(\mathrm{Ca}^{2+}\right)$ flux in the cytoplasm, which requires phospholipase $\mathrm{C} \gamma 2$ (PLC 2 ) activity. Increased $\mathrm{Ca}^{2+}$ subsequently activates the serine/threonine phosphatase calcineurin, which by dephosphorylating multiple serine residues in cytoplasmic NFAT proteins facilitates their activation and nuclear translocation. We have recently described an alternative mechanism of NFAT activation in pTCR-negative thymocytes, wherein IL-7-JAK3 activity activates NFATC1 in a tyrosine phosphorylation-dependent manner. ${ }^{33}$ NFAT activity in pTCR-negative thymocytes is not only critical for their survival and differentiation into T cells but is also indispensable in preventing the pathogenesis of $\mathrm{T}$ acute lymphoblastic leukemia. ${ }^{34}$

Furthermore, we and others have previously reported the involvement of NFAT proteins in B cell development and functions. ${ }^{35-38}$ Although NFAT proteins regulate multiple events in $B$ cell function, their role in early stages of $B$ cell differentiation in BM has not yet been investigated. Here we show that NFAT is active in pBCR-negative $B$ cells and that NFATc1 plays an indispensable and non-redundant role very early during $B$ cell differentiation. The serious defects in early $B$ cell differentiation in mice lacking NFATC1 activity in the hematopoietic system led to severe B cell lymphopenia, which further underscores the critical necessityof NFATc1 in facilitating B cell development.

\section{MATERIALS AND METHODS}

Mice

C57BL/6 wild-type (WT), Rag1 $1^{-1-}, \mathrm{Nfatc2}^{-1-}, \mathrm{Nfatc3}^{-1-}$, Nfatc2 $^{-1-}$ Nfatc3 $^{-1-}$, Nfatc1-eGfp-Bac tg, Vav-CreNfatc1 ${ }^{\mathrm{fl} /+}$, Vav-CreNfatc1 $1^{\mathrm{fl} / \mathrm{fl}}, 1 / 7^{-/-}, I 17 r^{-/-}$, Vav-CreNfatc1P2 $2^{\mathrm{fl} / \mathrm{fl}}$, Vav-CreNfatc $1 \mathrm{a} A^{\mathrm{fl} /+}$, and $V a v-C r e N f a t c 1 a A^{\mathrm{fl} / \mathrm{fl}}$ mice, all in the C57BL/6 background and of 3-8 weeks age unless mentioned otherwise, were used in the study. All animals were housed in the University of Würzburg central animal facility (ZEMM) following standard animal care procedures. All animals had ad libitum access to food and water. In each experiment, age-matched mice were used without any gender bias, and animals were handled humanely throughout the study.

Flow cytometry and cell sorting

All antibodies (Abs) used in flow cytometry and for isolation of

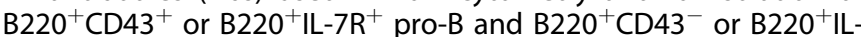
$7 R^{-}$pre- $B$ cells from $B M$ were purchased either from $B D$ Pharmingen or eBioscience. Anti-B220 (RA3-6BU), anti-CD43 (S7), anti-CD25 (PC61), anti-CD127 (B12-1), anti-CD3 (145-2C11), anti-lgM (R6-60.2), anti-IgD (11-26c), anti-CD21 (7G6), anti-CD23 (B3B4), anti-CD5 (53-7.3), anti-CD19 (1D3), anti-CD117 (2B8), antiBP1 (6C3), anti-CD24 (M1/69), and isotype-matched control Abs either directly conjugated to fluorochromes or to biotin were used throughout the study. Biotinylated Abs were revealed with secondary streptavidin-conjugated allophycocyanin or phycoerythrin-Cy5 (PE-Cy5) Abs. Flow cytometry and data analysis were performed following standard procedures using the FACSCalibur and FlowJo software.

For BM pro- and pre-B cell sorting, a single-cell suspension of BM cells from both hind limbs was prepared. WT BM cells were either stained with B220 and CD43 or with B220 and IL-7R Abs to sort $\mathrm{B} 220^{+} \mathrm{CD}_{4} 3^{+}$or $\mathrm{B} 220^{+} \mathrm{IL}_{-7 \mathrm{R}^{+}}$pro-B and $\mathrm{B} 220^{+} \mathrm{CD} 43^{-}$or

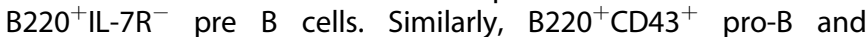
$\mathrm{B} 220^{+} \mathrm{CD} 43^{-}$pre-B cells were sorted from $\operatorname{Rag} 1^{-1-}$ mice BM. Cell sorting was performed using a FACSAria (BD Biosciences) flow cytometer and FACS DIVA software.

Immunofluorescence staining and immunoblotting

Sorted $\mathrm{BM} \mathrm{B} 220^{+} \mathrm{CD} 43^{+}$pro-B and $\mathrm{B} 220^{+} \mathrm{CD} 43^{-}$pre- $\mathrm{B}$ cells from WT or Rag $1^{-1-}$ mice or $\mathrm{B} 220^{+} \mathrm{IL}-7 \mathrm{R}^{+}$pro-B and $\mathrm{B} 220^{+} \mathrm{IL}^{-7 \mathrm{R}^{-}}$pre-B cells from WT mice were immunostained with NFATc1, NFATc2 (both from ImmunoGlobe), or NFATc3 (Santa Cruz) Abs following a previously published protocol. ${ }^{39}$ Counterstaining with 4,6-diamidino-2-phenylindole was performed to confirm nuclear staining. Image acquisition and data analysis were performed using a TCS SP2 Leica confocal microscope and software.

Whole-cell protein extracts from the WT pro- and pre-B cells were prepared as mentioned previously. ${ }^{40}$ Fifty micrograms of total protein was analyzed in an $8 \%$ sodium dodecyl sulfatepolyacrylamide gel electrophoresis (SDS-PAGE) and subjected to immunoblotting for detection of calcineurin (Cell Signaling Technology) and PLC 22 (Santa Cruz) levels. Actin was used as a loading control.

In vitro kinase assays

Rag $1^{-1-}$ pro-B cells $\left(10^{7}\right)$ were lysed in modified RIPA buffer, and the cell lysates were incubated with $5 \mu \mathrm{g}$ JAK3 Ab (Santa Cruz Biotech) overnight $(\mathrm{o} / \mathrm{n})$ at $4{ }^{\circ} \mathrm{C}$ to immunoprecipitate JAK3. Subsequently, 20 $\mu$ protein $A$ agarose beads were added to the cell lysate and incubated for $1 \mathrm{~h}$ at $4^{\circ} \mathrm{C}$ to capture the immunoprecipitated JAK3. The beads were washed one time in $1 \times$ tyrosine kinase buffer $(60$ $\mathrm{mM}$ HEPES, $5 \mathrm{mM} \mathrm{MgCl}, 5 \mathrm{mM} \mathrm{MnCl} 2,3 \mu \mathrm{M} \mathrm{Na} \mathrm{NO}_{4}$, and $2.5 \mu \mathrm{M}$ $\mathrm{DTT})$, and kinase reactions were set up by adding $10 \mu \mathrm{g}$ of glutathione S-transferase (GST)-NFATc1 or GST-STAT5 (signal transducer and activator of transcription factor 5) protein with $20 \mu \mathrm{M}$ ATP and $10 \mu \mathrm{Ci}$ YATP in radioactive assays at $22^{\circ} \mathrm{C}$ for $30 \mathrm{~min}$. For the non-radioactive assays, kinase reactions were performed without addition of YATP to the reaction mixture. Samples were analyzed by $6-8 \%$ SDS-PAGE followed by autoradiography for $\mathrm{Y}$-32P incorporation or immunoblotted to detect phospho-tyrosine.

\section{V-D-J recombination}

For analysis of rearranged Ig heavy and light chain genes, CDNA was synthesized from sorted $\mathrm{B} 22 \mathrm{O}^{+} \mathrm{CD} 43^{+}$pro-B cells from WT and Vav-CreNfatc $1^{\mathrm{f} / \mathrm{fl}}$ mice using the Miltenyi Biotec cDNA Synthesis Kit and protocol. Semiquantitative reverse transcriptase-polymerase chain reaction (RT-PCR) was performed to measure the expression of various rearranged heavy and light chain genes as well as germ line transcripts, using previously described primer pairs. ${ }^{41}$

Electrophoretic mobility shift assay (EMSA)

Nuclear extracts (NEs) prepared from freshly isolated BM B220 ${ }^{+} \mathrm{B}$ cells from $\operatorname{Rag}^{-1-}$ mice were analyzed in EMSA for DNA binding of NFATc1 at the Ebf1 promoter. The following oligonucleotides were used as EMSA probes: Ebf1 I: 5'-ATCTACACGCACGGAAAG GAAAGAAACATCTITGGTT-3', Ebf1 l: 5'-TGAGAGAGGAGGAGGA AAAAAGAGAGAGAAAAAAACT-3', and Ebf1 III: 5'-CTTGCCTGGTTGT GGAAAATGACACTTCAAGT-3', representing conserved NFAT sites I, II, and III at the Ebf1 promoter. An oligonucleotide containing the distal NFAT site at the murine $/ / 2$ promoter $\left(I / 2 P u-b_{d}\right)$ was used as a positive control: (-292) 5'-CCAAAGAGGAAAATTGTTCATACAGAAGGC-3' (-261). Five micrograms of nuclear proteins was

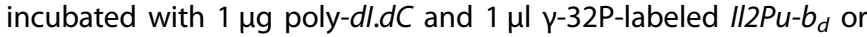
Ebf1 probes for $20 \mathrm{~min}$ on ice. For competition, a 100-fold molar excess of unlabeled cold probe was used, and in the supershift assays, $3 \mu \mathrm{g}$ NFATc1, NFATc2, or NFATc3 Abs were used to evaluate the specificity of the NFAT-DNA complexes. DNA-bound NFAT complexes were resolved in $5 \%$ non-denaturing gels using $0.5 \times$ TBE buffer at $140 \mathrm{~V}$ for $2 \mathrm{~h}$. Subsequently, the gels were transferred to Whatman filter papers and vacuum-dried for $2 \mathrm{~h}$. Dried gels were exposed to photographic film o/n at $-20^{\circ} \mathrm{C}$, and NFAT-DNA complexes were visualized in the autoradiogram. Free probe: labeled oligos without $\mathrm{NE}$, in each probe set, lane 1: NFAT-DNA complexes, lane 2: competition with cold oligos, lane 3: supershift with NFATc1 Abs, lane 4: supershift with NFATc2 Abs, and lane 5: supershift with NFATc3 Abs.

Chromatin immunoprecipitation (ChIP)

For each ChIP assay, 5-8 $\times 10^{6}$ WT pro-B cells were used following the Miltenyi Biotech ChIP protocol. Eight micrograms of NFATc1 

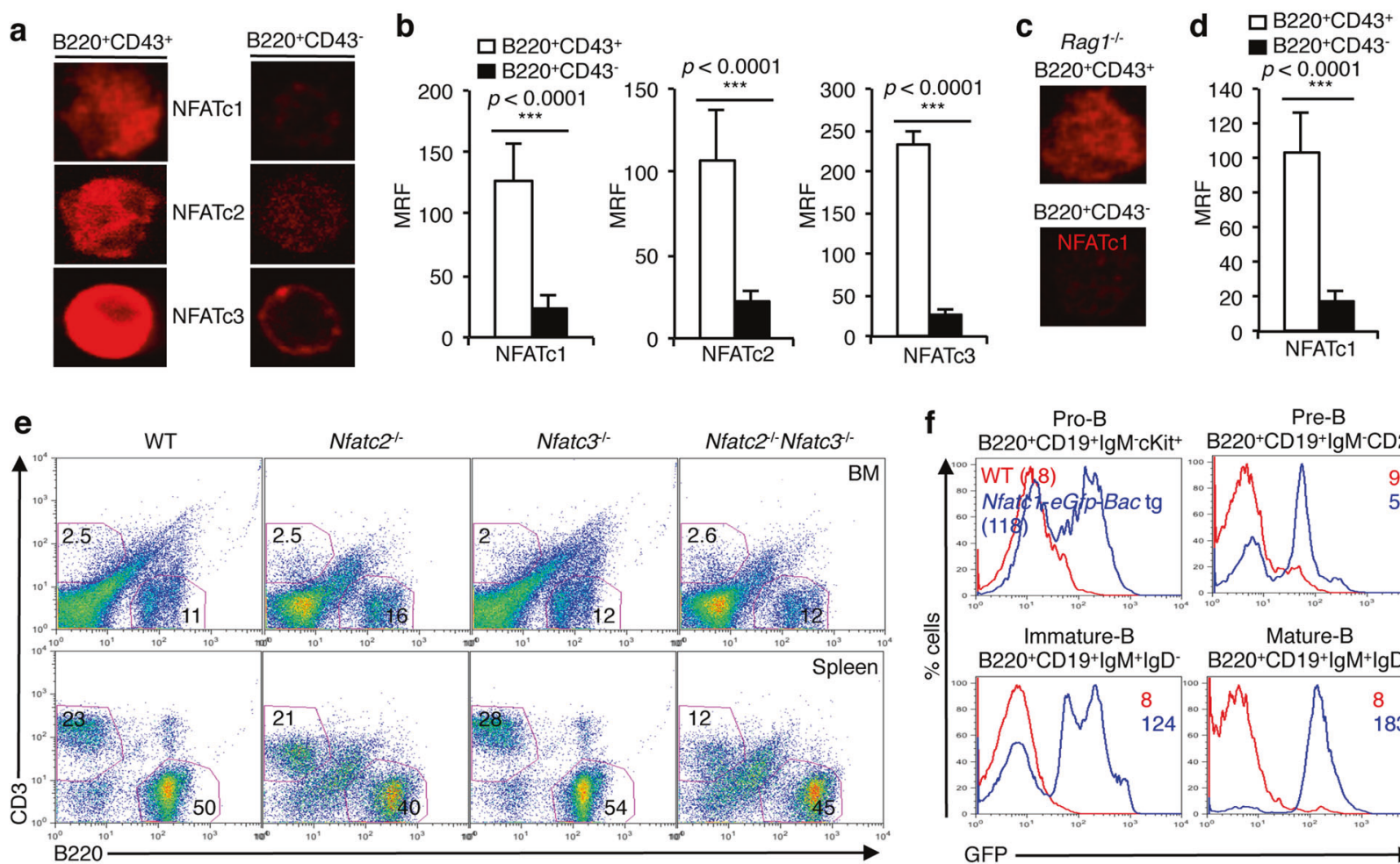

f

Pro-B

Pre-B B220+CD19+lgM-CKit ${ }^{+}$B220+CD19+lgM-CD25+
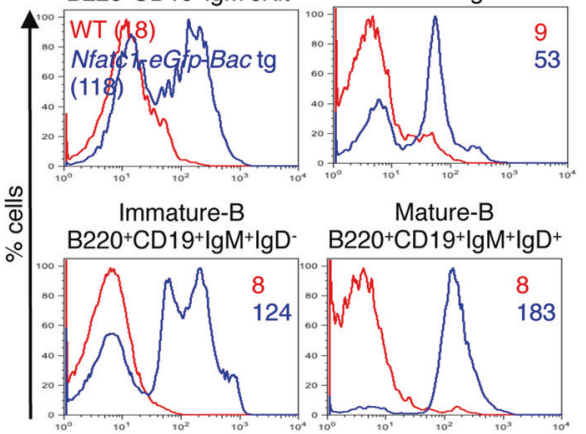

GFP

9

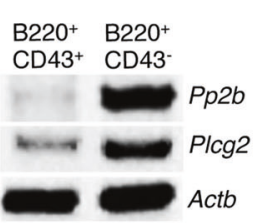

k

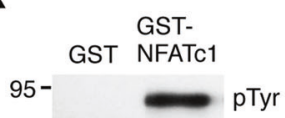

h

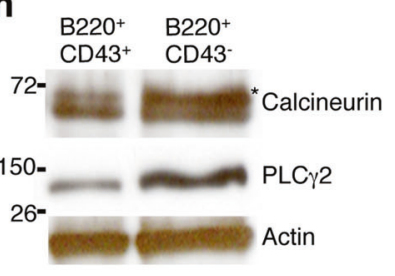

i

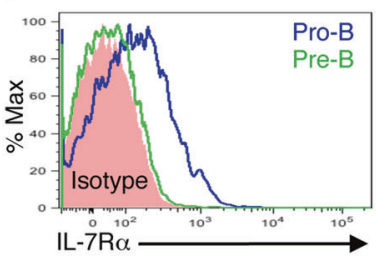

j

GST- GST-

GST STAT5a NFATC1

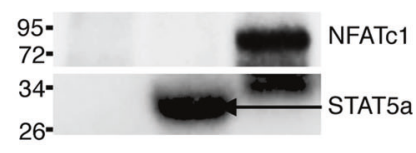

Fig. 1 NFAT Expression in pro-B cells. a Immunofluorescence revealing the expression of NFATC1, NFATC2, and NFATc3 in WT B220 ${ }^{+}$CD43 ${ }^{+}$pro$\mathrm{B}$ and $\mathrm{B} 220^{+} \mathrm{CD} 43^{-}$pre-B cells. b Quantification of the nuclear NFATc1 (pro-B; $n=32$ and pre-B; $n=81$ ), NFATc2 (pro-B; $n=38$ and pre-B; $n=$ 64), and NFATc3 (pro-B; $n=13$ and pre-B; $n=32$ ) levels in WT pro- and pre-B cells. c NFATc1 expression levels in Rag $1^{-1-}$ pro- and pre-B cells. d Quantification of the nuclear NFATc1 (pro-B; $n=14$ and pre-B; $n=28$ ) levels in Rag1 $1^{-1-}$ pro- and pre-B cells. e Flow cytometry profiles showing the distribution of $\mathrm{CD}^{+} \mathrm{T}$ cells and $\mathrm{B} 22 \mathrm{O}^{+} \mathrm{B}$ cells in the $\mathrm{BM}$ and spleen of $\mathrm{Nfatc2} 2^{-1-}, \mathrm{Nfatc}^{-/-}$, and $\mathrm{Nfatc2} 2^{-1-} \mathrm{Nfatc3^{- }}$ - mice

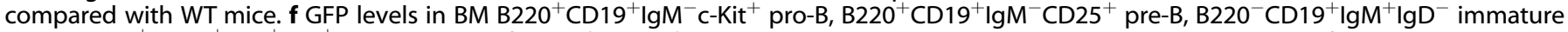
$\mathrm{B}$, and $\mathrm{B} 220^{+} \mathrm{CD}_{19}{ }^{+} \mathrm{IgM}^{+} \mathrm{IgD}^{+}$mature B cells from Nfatc1-eGfp-Bac tg reporter mice compared with WT mice. $\mathbf{g}$ Levels of calcineurin and Plcg2 mRNA expression in sorted WT B220 ${ }^{+} \mathrm{CD} 43^{+}$pro-B and $\mathrm{B} 220^{+} \mathrm{CD} 43^{-}$pre-B cells, as revealed by RT-PCR. $\mathbf{h}$ Immunoblot analysis of the protein levels of calcineurin and PLCg2 in sorted WT B220 ${ }^{+}$CD $43^{+}$pro-B and B220 ${ }^{+}$CD43 $3^{-}$pre-B cells. $\mathrm{i}$ IL-7R expression in WT pro- and pre-B cells. $\mathbf{j}$ In vitro kinase assays revealing JAK3-mediated phosphorylation of NFATc1 and STAT5. k Kinase assay followed by immunoblotting revealing JAK3-mediated tyrosine phosphorylation in NFATC1. Data are representative of three independent experiments $(n=3-7$ per group) and are shown as the mean \pm s.d., unpaired $t$ test $(\mathbf{b}, \mathbf{d})$

(Santa Cruz Biotech; sc-7294) or GST (A-6; Santa Cruz Biotech) Abs were used for immunoprecipitation $\mathrm{o} / \mathrm{n}$ at $4^{\circ} \mathrm{C}$. Protein-DNA complexes were precipitated, and DNA fragments bound to NFATc1 or GST were purified. The purified DNA fragments were used in PCR assays to amplify the Ebf1 promoter region bound to NFATc1 or GST. Primer sequences used to detect the Ebf1 promoter region are available in Supplementary Table 1.

Luciferase reporter assays

Murine Ebf1a or Ebf1b luciferase reporter constructs $(100 \mathrm{ng})^{42}$ were co-transfected independently along with $1000 \mathrm{ng}$ control vectors, expression vectors for a constitutively active STAT5 (STAT5ca) or NFATc1 (Nc1) alone, or with both STAT5 and NFATc1 together into 293 HEK cells using TurboFect Transfection Reagent
(Thermo Scientific ${ }^{\mathrm{TM}}$, \# R0531). At $24 \mathrm{~h}$ post-transfection, the cells were left unstimulated or stimulated with 12-O-tetradecanoylphorbol-13-acetate plus ionomycin ( $100 \mathrm{ng} / \mathrm{ml}$ each, Calbiochem) in the absence or presence of cyclosporin A (CsA, $100 \mathrm{ng} / \mathrm{ml})$ for $16 \mathrm{~h}$. Subsequently, luciferase activity depicting Ebf1a and Ebf1b promoter transactivation was measured using a MicroLumat LB 96P (EG\&G Berthold) luminometer.

\section{Photographs}

Photographs of the thymus, spleen, and lymph nodes (LNs) from WT, Vav-CreNfatcl ${ }^{\mathrm{fl} /+}$, and Vav-CreNfatcl $1^{\mathrm{fl} / \mathrm{fl}}$ mice or the spleen and LNs from WT and Vav-CreNfatc $1 P 2^{\mathrm{f} / \mathrm{fl}}$ mice were obtained using a Nikon Coolpix 4500 digital camera. Image processing was performed using the Adobe Photoshop software. 
Semiquantitative RT-PCR

Sorted $\mathrm{B} 220^{+} \mathrm{CD} 43^{+}$pro- and $\mathrm{B} 220^{+} \mathrm{CD} 43^{-}$pre-B cells from WT mice, pro-B cells from WT, Vav-CreNfatc $1^{\mathrm{fl} /+}$ and $\mathrm{Vav}$-CreNfatc $1^{\mathrm{f} / \mathrm{fl}}$ mice, sorted WT double-negative 3 (DN3) thymocytes, and VavCreNfatc1P2 $2^{\mathrm{f} / \mathrm{fl}}$ mouse thymocytes and pro-B cells were used to synthesize cDNA using the Miltenyi Biotec cDNA Synthesis Kit and protocol. Semiquantitative RT-PCR was performed to estimate the expression levels of the indicated genes. Primer sequences are available in the supplementary information online.

\section{Statistics}

Data are presented as the mean \pm s.d. Statistical significance was assessed using Student's $t$ test for comparison between two groups and analysis of variance for differences among groups.

\section{RESULTS}

NFAT activation in pro-B cells

To investigate whether TFs of the NFAT family play any role in B cell development in BM, we analyzed WT pro- and pre-B cells for the presence of NFAT proteins. Immunofluorescence analysis of

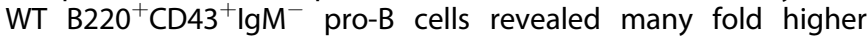

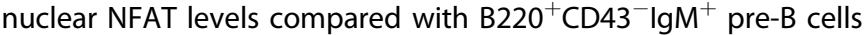
(Fig. $1 \mathrm{a}, \mathrm{b})$. Confirming this finding, analysis of pro-B $\left(\mathrm{B} 22 \mathrm{O}^{+} \mathrm{IL}_{-}-7 \mathrm{R}^{+}\right)$ and pre-B $\left(B 220^{+} I L-7 R^{-}\right)$cells isolated based on IL-7R expression revealed a similar NFAT distribution pattern (Supplementary Figure S1a and b). Irrespective of the markers used to identify pro- and pre-B cells, NFAT activation in pBCR-negative pro-B cells was higher for NFATC1, NFATC2, and NFATC3 compared with that in pBCR-positive pre-B cells (Fig. 1a, b and Supplementary Figure S1a and $b$ ). This observation was further consolidated by analyses of $R a g 1^{-1-}$ pro-B cells. Similar to WT pro-B cells, Rag $1^{-1}$ pro-B cells also exhibited high levels of nuclear NFATc1 (Fig. 1c, d), suggesting that NFAT proteins most likely play a role at the preBCR-negative stages of $B$ cell development in BM.

Owing to the high levels of NFATC1, NFATC2, and NFATC3 in pro-B cells, we next investigated which of the three NFAT family members is critical for early B cell development. Analysis of the B cell population in the BM of $N f a t c 2^{-1-}$ or $N f a t c 3^{-1-}$ mice revealed comparable proportions of $\mathrm{B}^{2} 2 \mathrm{O}^{+}$cells as in WT mice (Fig. 1e). Even the combined loss of both NFATC2 and NFATC3 (Nfatc2 ${ }^{-1-}$ Nfatc3 $^{-1-}$ ) did not alter $\mathrm{B}_{220^{+}}$population in BM (Fig. 1e), suggesting that NFATC2 and NFATC3 activity was most likely dispensable and that NFATc1 was the key NFAT protein regulating early B cell differentiation. This observation was supported by an earlier report that did not reveal any abnormality in early B cell development in $\mathrm{NfatC2}^{-1-}, \mathrm{NfatC}^{-1-}$, or the double-mutant mice, although mature splenic $B$ cell function was affected. ${ }^{36}$ NFATc1 expression in early B cell developmental stages was further confirmed, as $\mathrm{B}_{220}{ }^{+} \mathrm{CD} 19^{+} \mathrm{IgM}^{-} \mathrm{C}^{-\mathrm{Kit}^{+}}$pro-B cells from Nfatc1-eGfp-Bac transgenic (tg) reporter mice $34,37,43$ showed high GFP levels compared with those from WT mice (Fig. If and Supplementary Figure S1c). In fact, varying levels of GFP representing NFATC1 expression in pro-B, $\mathrm{B}_{22}{ }^{+} \mathrm{CD}_{19}{ }^{+} \mathrm{IgM}^{-} \mathrm{CD} 25^{+}$pre- $\mathrm{B}, \mathrm{B}_{22} 20^{+} \mathrm{CD}_{19}{ }^{+} \mathrm{IgM}^{+} \mathrm{IgD}^{-}$immature $\mathrm{B}$,

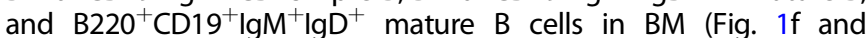
Supplementary Figure S1C) and in splenic B cells (Supplementary Figure S1d) suggest that NFATC1 activity plays an essential role in B cell development and function.

To gain insight into how NFAT is activated in pro-B cells, we analyzed the expression of components of the classical NFAT activation pathway, i.e., the PLC $\gamma 2$-calcium-calcineurin pathway. RT-PCR as well as immunoblot analysis showed that, compared with pre-B cells, pro-B cells expressed very low levels of Plcg2 and calcineurin (Pp2b) (Fig. 1g, h). Considering the high levels of NFAT (Fig. 1a-d and Supplementary Figure S1a and b) and insignificant expression of Plcg2 and calcineurin, it was apparent that NFAT activation was calcineurin independent in pro-B cells. This finding was supported by observations from previous reports showing normal early B cell development in the BM of calcineurin-deficient mice. $^{44,45}$

To understand the mechanism of NFAT activation, we investigated whether IL-7-JAK3 signaling also activates NFATC1 in pro-B cells as we have observed in thymocytes. ${ }^{33}$ Pro-B cells depend on IL-7 signaling for survival and differentiation. ${ }^{46,47}$ Accordingly, we detected high levels of IL-7R expression on pro-B compared with pre-B cells (Fig. 1i). To characterize the involvement of JAK3, we performed kinase assays with JAK3 immunoprecipitated from pro-B cells. In kinase assays, JAK3 phosphorylated NFATC1 as well as STAT5, indicating that, similar to observations in thymocytes, JAK3 plays the role of NFAT kinase, resulting in NFAT activation and nuclear translocation in pro-B cells (Fig. 1j). JAK3-mediated tyrosine phosphorylation of NFATc1 was confirmed by immunoblotting the kinase assay products with pTyr Abs (Fig. 1k). These observations suggest that NFAT activation in pro-B cells is dependent on IL-7-JAK3 signaling.

Impaired B cell development in the absence of NFATc1 NFATc1-deficient mice are embryonic lethal. ${ }^{48}$ To circumvent this problem and investigate the influence of NFATc1 on early B cell developmental stages, we analyzed $V a v-C r e N f a t c 1^{\text {fl/fl }}$ mice, in which NFATc1 activity was ablated in the hematopoietic system. Analysis of Vav-CreNfatc ${ }^{\text {fl/f }}$ mice showed a consistent and strong reduction in the size of primary lymphoid organs, such as the thymus, LNs, and spleen (Fig. 2a). A reduction of the thymus size in Vav-CreNfatc $1^{\mathrm{f} / \mathrm{fl}}$ mice due to developmental defects in thymocyte differentiation has been reported. ${ }^{33}$ The small LNs and spleen in Vav-CreNfatc $1^{\mathrm{f} / \mathrm{fl}}$ mice suggest possible defects in B cell development, as B cells constitute a major cell population in these organs. Accordingly, spleen cellularity was drastically reduced in VavCreNfatc $1^{\mathrm{flff}}$ mice compared with their littermate controls (Fig. 2b). Analysis of $T$ and $B$ cell distributions in the spleen revealed a strongly reduced $\mathrm{B} 220^{+} \mathrm{B}$ cell population in $\mathrm{Vav}$-CreNfatc $1^{\mathrm{fl} / \mathrm{fl}}$ mice (Fig. 2c, d). Further assessment of IgM and IgD-expressing B cells in the spleen confirmed that the loss of NFATc1 activity exerted a strong negative influence on B cell development (Fig. 2e, f).

In the absence of NFATc1 activity, very few $\mathrm{CD} 21^{+} \mathrm{CD} 23^{+}$ follicular and $\mathrm{CD} 21^{+} \mathrm{CD} 23^{-}$marginal zone $\mathrm{B}$ cells, as well as

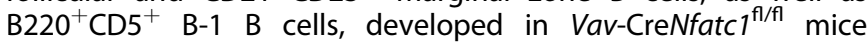
(Fig. $2 \mathrm{~g}-\mathrm{n}$ ). Additionally, $\operatorname{lgM}^{+} \mathrm{B}$ cells in the peritoneum were markedly reduced in Vav-CreNfatc ${ }^{\mathrm{fl} / \mathrm{fl}}$ mice compared with WT control mice (Fig. 2k, I). This strong phenotype in the absence of NFATc1 activity further confirmed that NFATC1 is the key NFAT protein essential for B cell development, and NFATC2 or NFATc3 cannot compensate for its loss. The reduced $\mathrm{B} 22 \mathrm{O}^{+} \mathrm{CD} 5^{+}$ population in $\mathrm{Vav}$-CreNfatc $7^{\mathrm{f} / \mathrm{fl}}$ mice is in agreement with previous reports concerning the requirement for NFATC1 for the development of these cells. ${ }^{35}$ Taken together, these abnormalities in B cell populations in the peripheral lymphoid organs of $\mathrm{Vav}^{-C r e N f a t c} 1^{\mathrm{f} / \mathrm{fl}}$ mice indicate a defect in B lymphopoiesis in the BM.

\section{B cell development in BM is critically dependent on NFATc1} activity

To elucidate the precise stage at which B cell development is affected owing to the absence of NFATC1 activity, we analyzed B cell differentiation in the BM of $\mathrm{Vav}$-CreNfatc $7^{\mathrm{fl} / \mathrm{fl}}$ mice. BM cellularity as well as $\mathrm{BM} \mathrm{B220^{+ }}$ B cell numbers were dramatically reduced in Vav-CreNfatc ${ }^{\text {fl/fl }}$ mice, although an increase in the percentage of distributed $\mathrm{B}^{2} 2 \mathrm{O}^{+}$cells was observed (Fig. 3a, b). Further analysis revealed a strong reduction in both the percentage of distribution and in the absolute numbers of the $\mathrm{BM} \mathrm{B} 220^{+} \mathrm{CD}_{4} 3^{+}$pro-B cells (Fig. 3c, d), as well as an increase in the percentage but a marked reduction in the absolute numbers

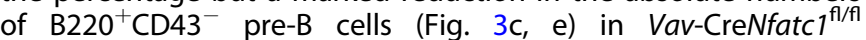
compared with WT mice. The $B 220^{+} \mathrm{CD} 43^{+}$population can be further subdivided into three subsets based on the surface expression of heat-stable antigen (CD24) and BP1 molecules, i.e., 


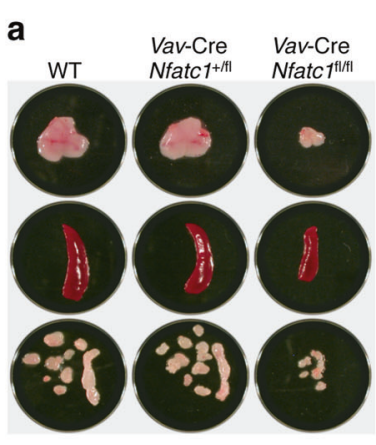

e

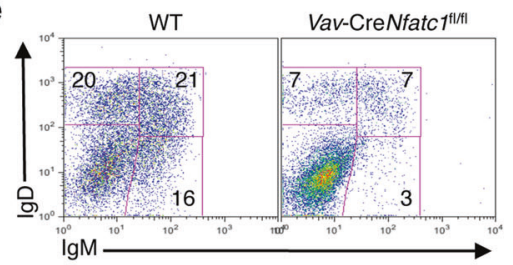

g
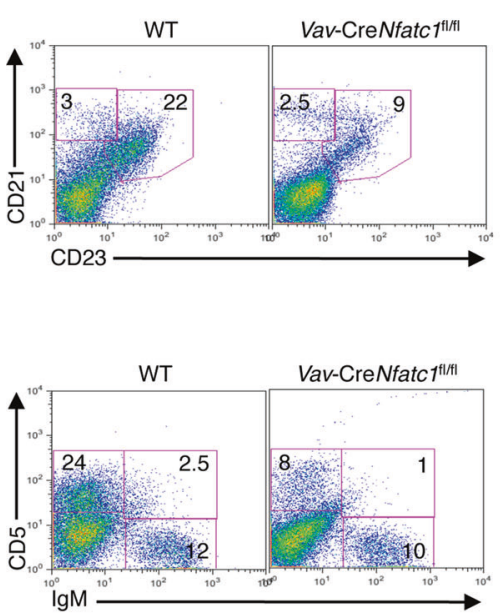

k

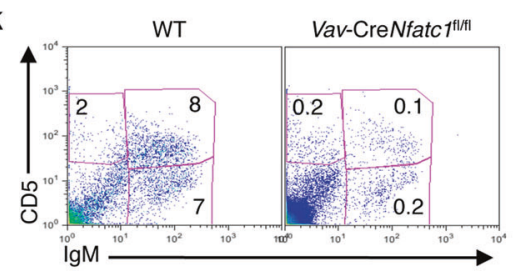

m

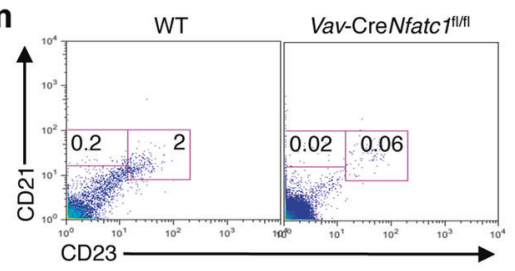

WT

- Vav-CreNfatc $1^{\text {fl/1/1 }}$

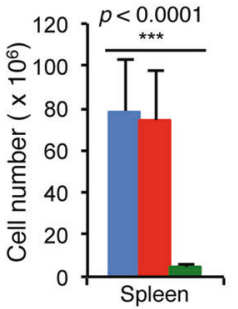

C

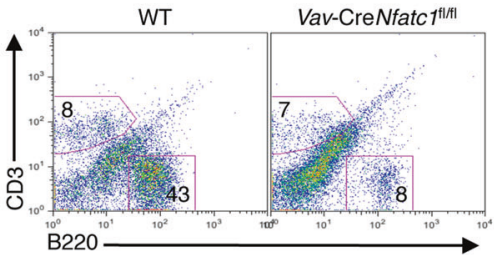

d $\quad$ WT

- Vav-CreNfatc $1^{\mathrm{fl} / \mathrm{+}}$

- Vav-CreNfatc ${ }^{\text {trif }}$

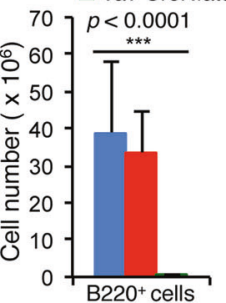

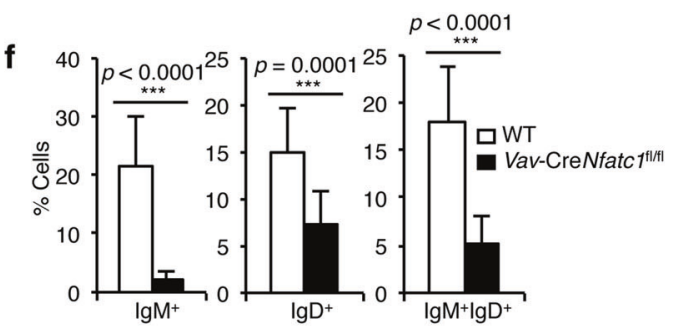
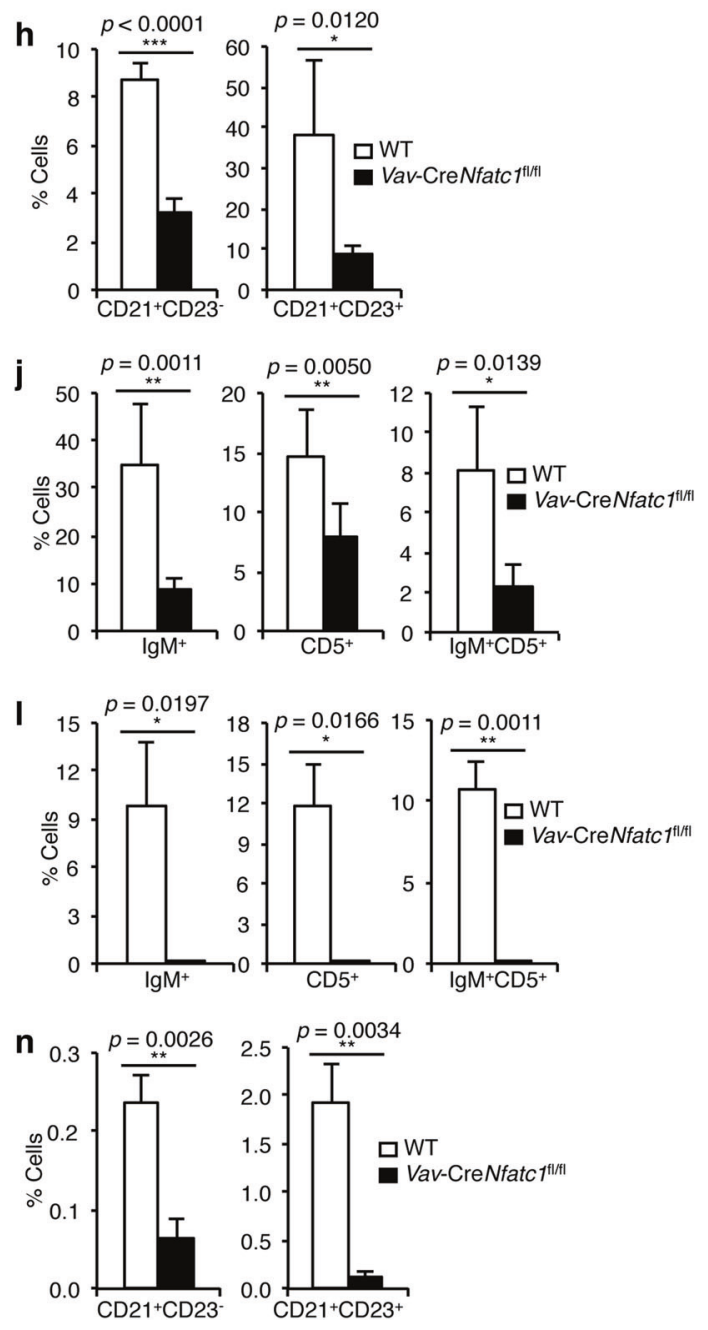

$\mathrm{B} 220^{+} \mathrm{CD} 43^{+} \mathrm{CD}_{24}{ }^{-} \mathrm{BP} 1^{-}$pre-pro-B cells, $\mathrm{B} 220^{+} \mathrm{CD} 43^{+} \mathrm{CD} 24^{+} \mathrm{BP} 1^{-}$ pro- $\mathrm{B}$ cells, and $\mathrm{B} 220^{+} \mathrm{CD} 43^{+} \mathrm{CD} 24^{+} \mathrm{BP} 1^{+}$large pre-B cells. ${ }^{49}$ Our analysis revealed that, in $\mathrm{Vav}$-CreNfatc $1^{\mathrm{fl} / \mathrm{fl}}$ mice, B cell development was arrested at the $\mathrm{B} 220^{+} \mathrm{CD} 43^{+} \mathrm{CD} 24^{-} \mathrm{BP} 1^{-}$pre-pro-B cell stage (Fig. $3 f, g$ ). Very few cells differentiated to the later stages, resulting in a dramatically reduced $B$ cell population in the BM and peripheral lymphoid organs (Figs. $3 \mathrm{~b}$ and $2 \mathrm{~d}$ ). Similar to the

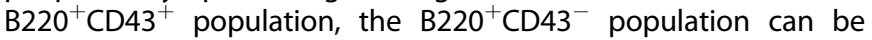
divided into three subsets based on the expression of $\operatorname{lgM}$

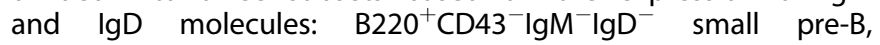


Fig. 2 Impaired B cell development in Vav-CreNfatc $7^{\mathrm{fl} / \mathrm{fl}}$ mice. a Photographs of the thymus, spleen, and LNs from Vav-CreNfatc $7^{\mathrm{fl} / \mathrm{fl}}$ mice compared with littermate Vav-CreNfatc $1^{\mathrm{f} /+}$ and WT mice. b Total splenocyte numbers in WT $(n=8), \mathrm{Vav}-\mathrm{CreNfatc} 1^{\mathrm{fl} /+}(n=8)$, and $\mathrm{Vav}$ CreNfatc $f^{\mathrm{fl} / \mathrm{fl}}(n=9)$ mice. c Flow cytometry showing the distribution of $\mathrm{CD}^{+} \mathrm{T}^{\mathrm{T}}$ and $\mathrm{B} 22 \mathrm{O}^{+} \mathrm{B}$ cells in the spleen from Vav-CreNfatc $7^{\mathrm{f} / \mathrm{fl}}$ mice compared with WT controls. d Absolute numbers of $\mathrm{B}_{2} 20^{+} \mathrm{B}$ cells in the spleen from Vav-CreNfatc $f^{\mathrm{f} / \mathrm{fl}}(n=9)$ mice compared with littermate control ( $n=8$ for both Vav-CreNfatc $1^{\mathrm{fl} /+}$ and WT) mice. e, $\mathbf{f}$ Distribution of $\operatorname{lgM}^{+}$and $\operatorname{lgD}^{+}$B cells in the spleen (e) and quantification of the $\%$ cells (f) from WT and Vav-CreNfatc $7^{\mathrm{f} / \mathrm{fl}}$ mice. $\mathbf{g}, \mathbf{h}$ Follicular and marginal zone B cell distribution in the spleen (g) and quantification of the percentage of cells (h) from Vav-CreNfatc ${ }^{\mathrm{t} / \mathrm{fl}}$ mice compared with littermate control mice as revealed by CD21 and CD23 staining. i, $\mathbf{j}$ Distribution of splenocytes according to CD5 and IgM expression (i) and quantification of the percentage of cells (j) in WT and VavCreNfatc $f^{\mathrm{fl} / \mathrm{fl}}$ mice. $\mathbf{k}$, I Distribution of $\mathrm{CD}^{+}$and $\operatorname{lgM}^{+}$cells $(\mathbf{k})$ and quantification of the percentage of cells (I) in the peritoneum of VavCreNfatc ${ }^{\text {fl/fl }}$ mice compared with WT controls. $\mathbf{m}$, $\mathbf{n}$ Distribution of follicular and marginal zone $B$ cells ( $\mathbf{m}$ ) and quantification of the percentage of cells $(\mathbf{n})$ in the peritoneum of Vav-CreNfatc $1^{\mathrm{f} / \mathrm{fl}}$ mice compared with WT controls. Numbers within each dot plot represent the percentage of the respective population. Data represent one of the three independent experiments $(n=3$ per group) and are shown as the mean \pm s.d., one-way ANOVA (b, d), and unpaired $t$-test $(\mathbf{f}, \mathbf{h}, \mathbf{j}, \mathbf{I}, \mathbf{n})$

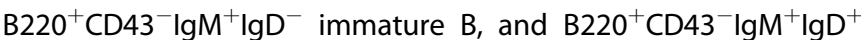
mature $\mathrm{B}$ cells. ${ }^{49}$ In Vav-CreNfatc $1^{\mathrm{f} / \mathrm{fl}}$ compared with their littermate control mice, there were very few $\mathrm{B} 220^{+} \mathrm{CD} 43^{-} \mathrm{Ig}$ $\mathrm{M}^{+} \mathrm{IgD}^{-}$immature and $\mathrm{B}^{2} 20^{+} \mathrm{CD}^{-} 3^{-} \mathrm{IgM}^{+} \mathrm{IgD}^{+}$mature $\mathrm{B}$ cells, confirming a developmental arrest at the pro-B cell stage due to the absence of NFATc1 activity (Fig. 3h, i).

We have previously shown that the abolition of NFATc1 activity in $B$ cells (Mb1-CreNfatc $1^{\text {fl/fl }}$ mice) leads to defects in mature B cell function, but it does not influence the early $B$ cell differentiation stages in BM. ${ }^{37}$ Correlating our observations with that from $\mathrm{Mb}$ 1CreNfatc ${ }^{\mathrm{f} / \mathrm{fl}}$ mice, it is apparent that NFATc1 activity at a stage where the immature $B$ cells still have not acquired the $p B C R$ is critical for B cell development. To investigate the basis behind the differentiation block, we assumed that most likely lack of NFATc1 activity is impairing the IL-7 responsive stages of B cell

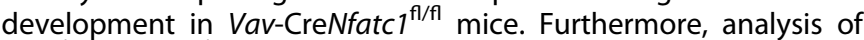
$\| 7 r^{-1-}$ and $I I 7^{-1-}$ mice revealed a similar developmental arrest at the early B cell differentiation stage, as observed in Vav$\mathrm{CreNfatc}^{\mathrm{fl} / \mathrm{fl}}$ mice (Fig. 3j and Supplementary Figure S2a). These observations suggest that NFATc1 activation is indispensable for B cell development in BM.

Loss of NFATc1 dysregulates Ebf1 and the expression of other B lineage-specific genes

To gain insight into the defects in pro-B cell development in the absence of NFATc1 activity, we analyzed the expression of various molecules implicated to regulate B cell development. RT-PCR analysis revealed NFATc1 was specifically and efficiently deleted in pro-B cells of $\mathrm{Vav}$-CreNfatc $1^{\mathrm{fl} / \mathrm{fl}}$ mice (Fig. 4a). However, normal expression of NFATC2 and reduced expression of NFATc3 were not sufficient to restore the B cell phenotype in $\mathrm{Vav}$-CreNfatc $1^{\mathrm{fl} / \mathrm{fl}}$ mice, ruling out any compensation by these NFAT family members (Fig. 4a). Interestingly, analysis of molecules that are critically involved in $\mathrm{B}$ lineage commitment and specification did not reveal any alterations in the expression of Spi1 (PU.1), Tcf3 (E47), Tcf12 (HEB), Oct1, Oct2, Id 1, Id2, and Id3, ruling out any involvement of NFATc1 in the regulation of these genes (Fig. 4a). In fact, all these genes were slightly upregulated in $\mathrm{Vav}$-CreNfatc $1^{\mathrm{f} / \mathrm{fl}}$ pro-B cells. Several NF-KB family members have been shown to regulate $B$ cell development, as evidenced in studies examining gene-deficient mice. ${ }^{50,51}$ However, we observed an elevated level of Rela (P65), Relb, and Nfkb2 expression in Vav-CreNfatc $1^{\mathrm{fl} / \mathrm{fl}}$ compared with WT mouse pro-B cells (Fig. 4a). Interestingly, we observed a strong downregulation of Ebf1 expression as well as reduced expression of Foxo 1 and Pax5 in Vav-CreNfatc ${ }^{\mathrm{f} / \mathrm{fl}}$ compared with WT mouse pro-B cells (Fig. 4a). Reduced Pax5 expression could be due to a downregulation of EBF1 activity, as it has been reported that Pax5 expression is regulated by EBF1. ${ }^{16}$ Thus EBF1 seems to be the prime target of NFATC1 during pro-B cell development.

Based on our analysis, the B cell developmental defect in VavCreNfatc $1^{\mathrm{f} / \mathrm{fl}}$ mice clearly occurs at a similar stage as that in IL-7- or IL-7R-deficient mice (Fig. 3j and Supplementary Figure S2a). ${ }^{3,4}$ To exclude the possibility that the absence of NFATc1 activity impairs
IL-7-STAT5 signaling, we investigated the expression of all components of the IL-7 signaling pathway. Normal expression of II7ra, Jak3, Stat5a, and Stat5b genes in Vav-CreNfatc ${ }^{\text {fl/fl }}$ compared with WT mouse pro-B cells (Fig. $4 b$ ) excluded the possibility that the absence of STAT5 activity was responsible for the arrested B cell development in Vav-CreNfatc $1^{\text {fl/fl }}$ mice. The B cell developmental arrest in IL-7- and IL-7R-deficient mice has been attributed to the absence of EBF1 expression. ${ }^{24}$ The lack of EBF1 expression in $\mathrm{Vav}$-CreNfatc1 ${ }^{\mathrm{fl} / \mathrm{fl}}$ mice (Fig. 4 a) resembles to that in IL-7 and IL7R-deficient mice and suggests that NFATc1 is an important downstream target of IL-7 signaling.

In addition to the defect in Ebf1 expression, pro-B cells in Vav$\mathrm{CreNfatc}^{\mathrm{f} / \mathrm{fl}}$ displayed a strong downregulation of the Rag1, Rag2, and Tdt (Dntt) genes involved in the recombination and rearrangement of $\mathrm{lg}$ genes. Furthermore, Vav-CreNfatc $1^{\mathrm{fl} / \mathrm{fl}}$ pro-B cells lacked expression of $\lambda 5$ (Igll1), VpreB, Ig-a (Cd79a), and Ig- $\beta$ $(C d 79 b)$, all of which are components of the pBCR complex. These observations suggest that NFATc1 is a critical player in B cell development, and the absence of NFATc1 can have profound effect on B lymphopoiesis. We also observed similar defects in early-B cell differentiation-specific gene expression in IL-7 signaling-deficient pro-B cells, which was in agreement with previously published reports (Supplementary Figure S2b).

EBF1 expression in pro-B cells is regulated from two distinct promoters, leading to the expression of EBF1a and EBF1 $\beta$ isoforms. ${ }^{42}$ It has been reported that EBF1 $\beta$ is the major isoform expressed in pro-B cells and regulates the expression of EBF1a. In investigations to determine which EBF isoform was affected by the absence of NFATc1, we observed that both Ebf1a and Ebf1b were strongly downregulated in $\mathrm{Vav}$-CreNfatc $1^{\mathrm{fl} / \mathrm{fl}}$ mouse pro-B cells (Fig. 4c), suggesting that EBF1 is a target of NFATc1 in pro-B cells.

\section{NFATc1 regulates EBF1 expression in pro-B cells}

To investigate whether NFATC1 transcriptionally regulates EBF1 expression, we searched for the NFAT DNA-binding consensus sequence $5^{\prime}$-GGAAA-3' approximately $1 \mathrm{~kb}$ upstream of the Ebf1b transcriptional start site. We detected five NFAT consensus sequences in this upstream sequence, four of which were conserved in mouse and human (Fig. 5a). To verify NFATc1 binding to these conserved sites, we performed EMSAs with NE prepared from WT pro-B cells. As shown in Fig. 5b, NFATc1 binding was detected in sites I, II, and III, with the second and third conserved sites showing a higher affinity in comparison to site I. NFATc1 binding to site IV was weaker than to the other three conserved sites (data not shown). NFATc1 binding to these sites was abolished specifically by an Ab against NFATc1, whereas the complex remained unaltered in the presence of Abs against either NFATc2 or NFATc3 (Fig. 5b). Furthermore, strengthening our observations regarding NFATc1-mediated regulation of Ebf1 expression, ChIP assays revealed the in vivo NFATc1 binding at the Ebf1 promoter in WT pro-B cells (Fig. 5c). Supporting these observations, in reporter assays, we observed minimal transactivation of the Ebf1b promoter by NFATc1 (Fig. 5d). However, 
a

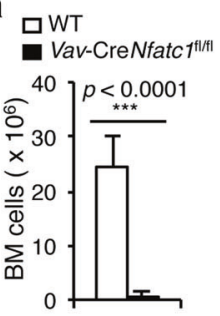

b aWT

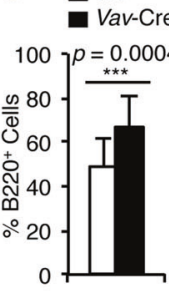

C

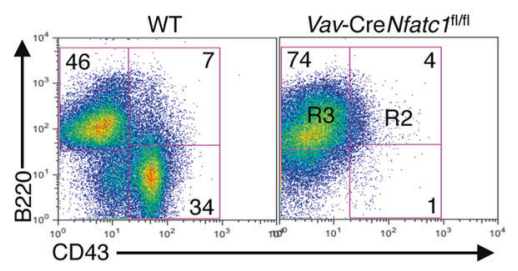

d

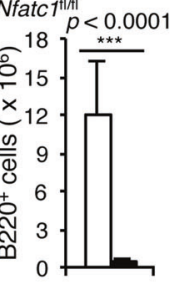

d aWT

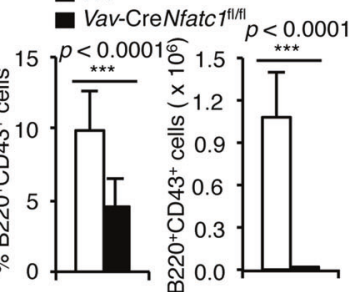

e

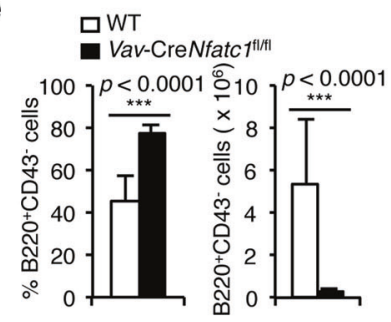

f

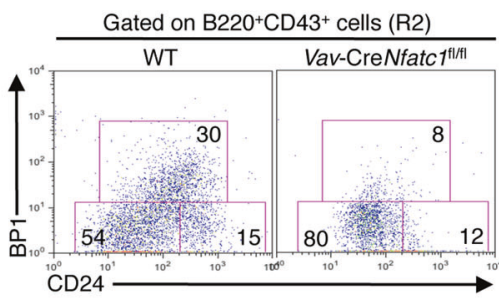

g

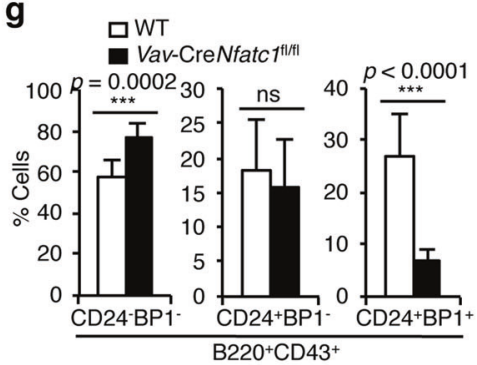

h

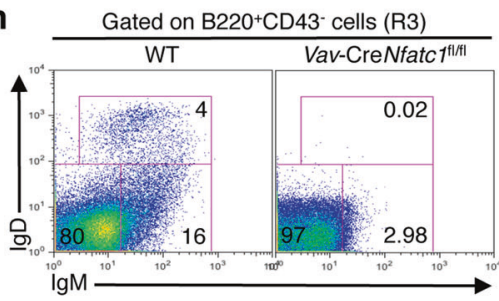

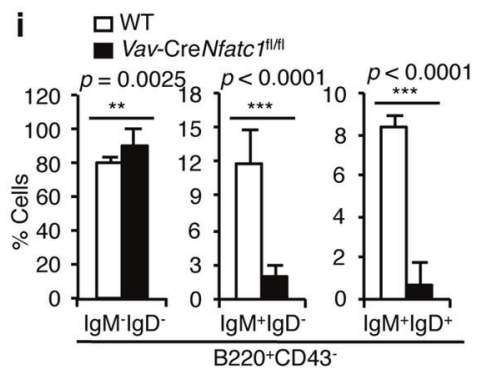

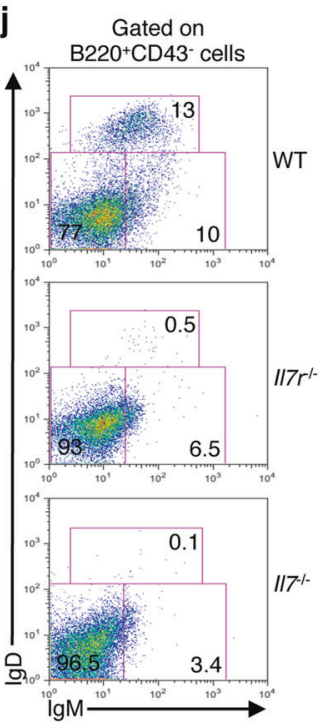

Fig. 3 Lack of NFATC1 activity arrests pro-B cell differentiation to pre-B cells. a Cellularity in the BM of WT and Vav-CreNfatc1 ${ }^{\text {fl/fl }}$ mice. $\mathbf{b}$ B220 $0^{+}$B cell distribution both as a percentage of the population and as the absolute numbers in the BM of WT and Vav-CreNfatc $1^{\mathrm{f} / \mathrm{fl}}$ mice. c Flow cytometry profiles showing the distribution of BM cells based on B220 and CD43 expression in WT and Vav-CreNfatc $7^{\mathrm{fl} / \mathrm{fl}}$ mice. d Quantification of the percentage of distribution and absolute numbers of $B 220^{+} C D 43^{+}$pro-B cells in the BM of WT and Vav-CreNfatc1 ${ }^{\mathrm{f} / \mathrm{fl}}$ mice. e Quantification of the percentage of distribution and absolute numbers of $\mathrm{B} 22 \mathrm{O}^{+} \mathrm{CD} 43^{-}$pre-B cells in the BM of WT and Vav-CreNfatc $7^{\mathrm{f} / /}$ ${ }^{\mathrm{fl}}$ mice. f, $\mathbf{g ~ B} 220^{+} \mathrm{CD} 43^{+} \mathrm{CD} 24^{-} \mathrm{BP} 1^{-}$pre-pro-B, B220 ${ }^{+} \mathrm{CD} 43^{+} \mathrm{CD} 24^{+} \mathrm{BP} 1^{-}$pro- $\mathrm{B}$, and $\mathrm{B} 220^{+} \mathrm{CD} 43^{+} \mathrm{CD} 24^{+} \mathrm{BP} 1^{+}$large pre-B cell distributions in the BM (f) and the quantification of their percentage of distribution (g) from Vav-CreNfatc1 $1^{\text {fl/fl }}$ mice compared with WT controls.

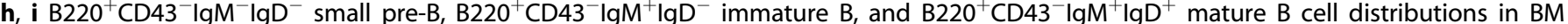
(h) and the quantification of their percentage of distribution (i) from WT and Vav-CreNfatc $1^{\mathrm{fl} / \mathrm{fl}}$ mice. $\mathbf{j}$ Distribution of $\mathrm{B}$ cells gated on the $\mathrm{B} 22 \mathrm{O}^{+} \mathrm{CD} 43^{-}$population in BM from $117^{-1-}$ and $117 \mathrm{r}^{-1-}$ mice based on IgM and IgD expression compared with littermate WT mice. Numbers inside each dot plot represent the percentage of the respective population. Data represent one of three independent experiments $(n=3$ per group) and are shown as the mean \pm s.d., unpaired $t$ test

NFATc1 in combination with STAT5 increased Ebf1b promoter activity by several fold, and this effect was reduced when NFATc1 activity was blocked by CsA treatment (Fig. 5d). Interestingly, NFATc1 exerted a similar influence on the Ebf1a promoter, suggesting that both Ebfla and Ebf1b are transcriptionally regulated by NFATc1 (Fig. 5d), which supports our observations of strongly reduced expression of both isoforms in $\mathrm{Vav}$-CreNfatc $\mathrm{f}^{\mathrm{fl} / \mathrm{fl}}$ pro-B cells (Fig. 4c). These observations suggest that, downstream of IL-7 signals, NFATC1 and STAT5 synergistically regulate Ebf1 activity and critically influence early $B$ cell differentiation in BM.
NFATc1 regulates Ig gene rearrangement in pro-B cells As $B$ cell development in $\mathrm{Vav}$-CreNfatc $1^{\mathrm{fl} / \mathrm{fl}}$ mice was arrested at the pro- $B$ cell stage, we analyzed the rearrangement status of the $\mathrm{lgH}$ and $\mathrm{lg} \mathrm{L}$ chain locus. RT-PCR analysis revealed that, compared with WT pro-B cells, transcripts for either $\mathrm{K}$ - or $\lambda$-light chains as well as the proximal and distal $\mathrm{V}_{\mathrm{H}}$ segment containing the $\lg \mathrm{H}$ chain were negligible in $\mathrm{Vav}$-CreNfatcl $1^{\mathrm{f} / \mathrm{fl}}$ pro-B cells (Fig. 6). Correspondingly, germline transcripts for distal $\mathrm{V}_{\mathrm{H}}$ segments were absent in $\mathrm{Vav}$-CreNfatc $1^{\mathrm{f} / \mathrm{fl}}$ pro-B cells, indicating a defect in $\mathrm{lg}$ heavy chain locus accessibility (Fig. 6) and raising the possibility of NFATc1 acting as a facilitator of Ig gene locus accessibility and 


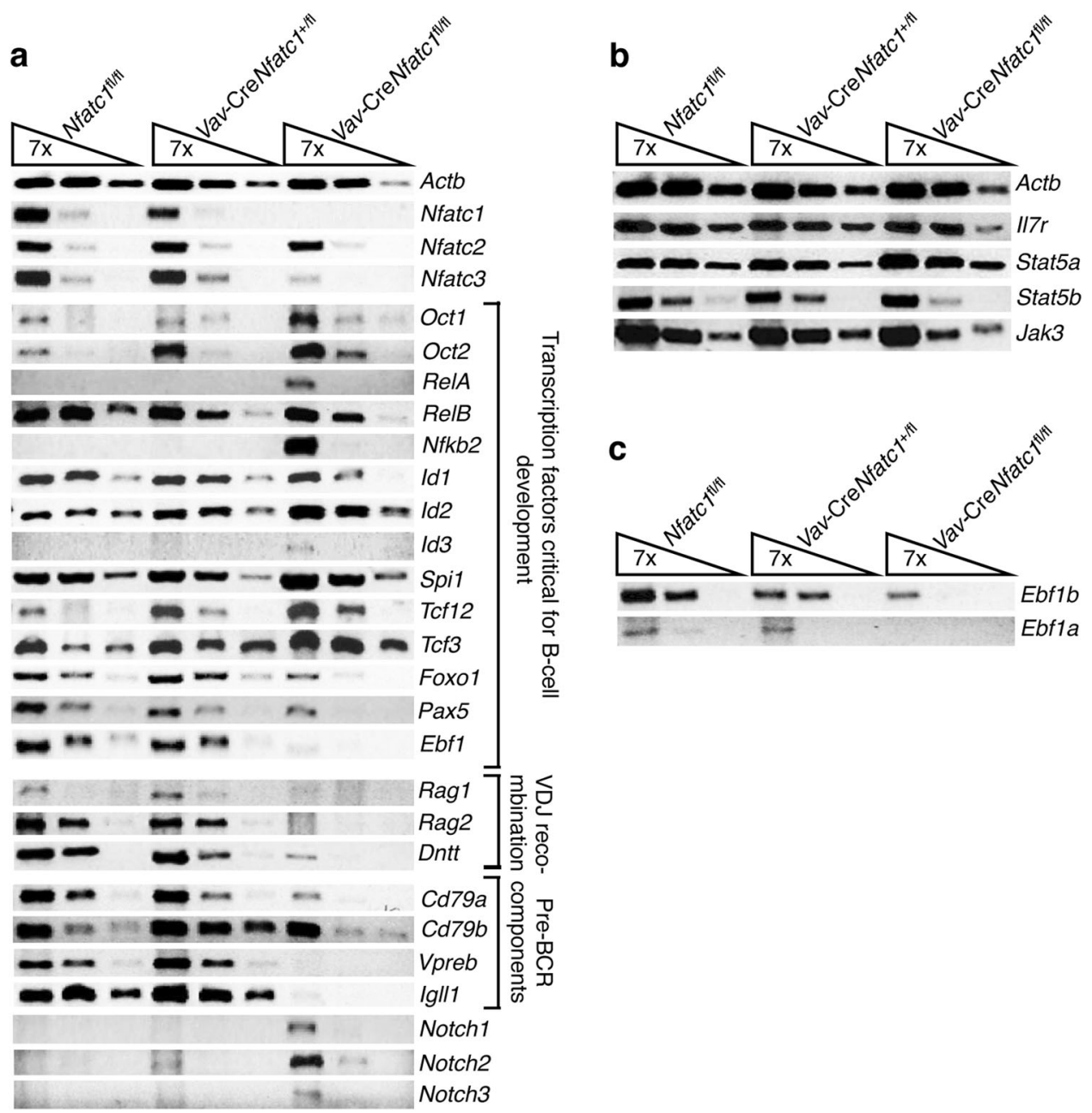

Fig. 4 Abnormal B cell development-specific gene expression in Vav-CreNfatc $1^{\mathrm{fl} / \mathrm{fl}}$ pro-B cells. a RT-PCR analysis of gene expression, including transcription factors that regulate $B$ cell development, molecules associated with V-D-J recombination, pBCR components, and other signaling molecules, in Vav-CreNfatc $1^{\mathrm{T} / \mathrm{fl}}$ pro-B cells compared with littermate control mice. b $\| / 7 r$, Jak3, Stat5a, and Stat5b gene expression in pro-B cells from the indicated mice. c Levels of Ebf1a and Ebf1b isoform expression in Vav-CreNfatc $1^{\mathrm{fl} / \mathrm{fl}}$ mice compared with littermate control mice. Data are representative of two independent experiments with cDNA prepared from sorted cells collected from pooled BM cells from multiple mice for each genotype in each experiment

rearrangement. This result further supports a role for NFATc1 downstream of IL-7 signaling in the regulation of $\mathrm{B}$ cell developmental events, as IL-7 signaling has been reported to regulate $\mathrm{lgH}$ locus accessibility. ${ }^{52,53}$

A threshold level of NFATc1 activity is essential for B cell differentiation

NFATc1 is expressed from two distinct promoters. NFATc1a isoforms are directed from the distal P1 and NFATC1 $\beta$ isoform expression is directed from the proximal P2 promoter. ${ }^{54}$ We have recently demonstrated distinct developmental stage-specific Nfatc1 promoter activity during thymocyte differentiation with NFATC1 $\beta$ isoforms expressed in pTCR-negative cells and both NFATc1 $a$ and NFATc1 $\beta$ activity in pTCR-positive thymocytes. ${ }^{34}$ To assess whether a similar pattern of NFATC1 promoter activity occurs during B cell development, we evaluated Nfatc1a and Nfatc1b-specific transcripts in WT pro- and pre-B cells. We observed strong P2 promoter-derived NFATc1 $\beta$ expression in $\mathrm{B} 220^{+} \mathrm{CD} 43^{+}$pro-B cells, whereas pBCR-positive $\mathrm{B} 220^{+} \mathrm{CD} 43^{-}$pre$B$ cells showed strong expression of both NFATC1 $\beta$ and P1 promoter-derived NFATc1a (Fig. 7a). Thus NFATC1 $\beta$ isoforms probably play a critical role in the differentiation of pro-B cells in the absence of $\mathrm{pBCR}$ signaling, and $\mathrm{pBCR}$-bearing $\mathrm{B}$ cells require both NFATc1 $\beta$ and NFATc1a for further differentiation into mature $B$ cells.

To further investigate whether exclusive NFATc1 $\beta$ activity is really critical, and whether $B$ cell differentiation is impaired in the absence of P2 promoter activity, we analyzed Vav-CreNfatc1P2 ${ }^{\text {fl/fl }}$ mice. ${ }^{34}$ However, preliminary analysis of the LNs, spleen, and BM in these mice did not reveal any perturbations in size or cellularity, suggesting that $B$ cell differentiation was normal in the absence of P2-derived NFATc1 $\beta$ (Fig. 7b, c). Further characterization revealed a normal distribution of $\mathrm{B}^{2} 2 \mathrm{O}^{+} \mathrm{B}$ cells in the $\mathrm{BM}$ and spleen of these mice (Fig. 7d and Supplementary Figure S3a). Additionally, the unaffected distribution of $\mathrm{B}_{22} \mathrm{O}^{+} \mathrm{IgM}^{+}$and $\mathrm{B}^{2} 2 \mathrm{O}^{+} \mathrm{IgD}^{+} \mathrm{B}$ cells and of the follicular $\left(\mathrm{CD} 21^{+} \mathrm{CD} 23^{+}\right)$and marginal zone $\left(\mathrm{CD} 21^{+} \mathrm{CD} 23^{-}\right) \mathrm{B}$ cells in the spleen of $\mathrm{Vav}-\mathrm{CreP} 2^{\mathrm{f} / \mathrm{fl}}$ mice revealed that B cell development was comparable to that in WT mice (Fig. 7e and Supplementary Figure S3b). These observations are in stark contrast to the arrested B cell development in VavCreNfatc $1^{\mathrm{f} / \mathrm{fl}}$ mice, which led us to investigate whether NFATc1 activity was still present in pro-B cells in Vav-CreNfatc1P2 ${ }^{\mathrm{fl} / \mathrm{fl}}$ mice. RT-PCR analysis revealed a complete loss of P2 promoter activity, but surprisingly, in the absence of $N f a t c 1 b$, robust expression of Nfatc1a directed from the P1 promoter was observed in VavCreNfatc1P2 ${ }^{\mathrm{f} / \mathrm{fl}}$ mice (Fig. 7f). Thus the normal B cell development 
a

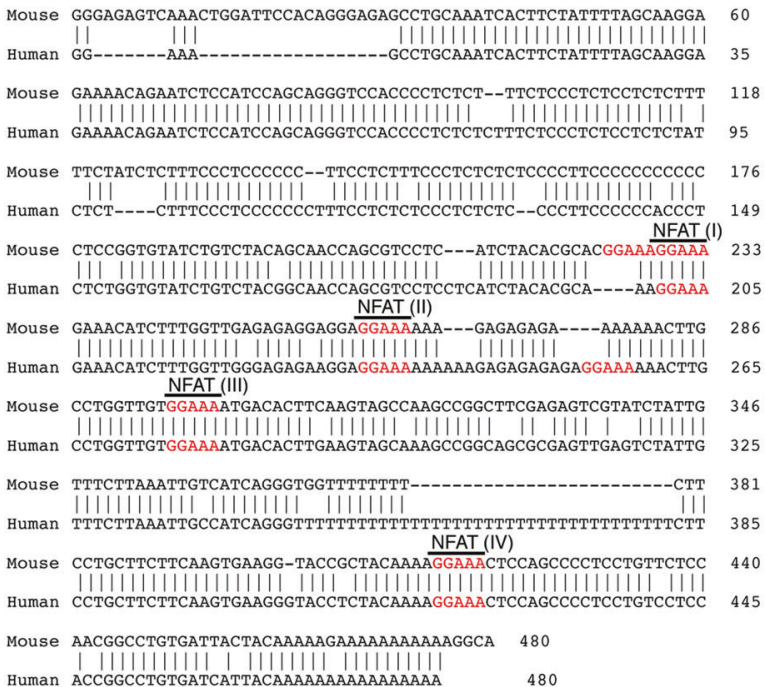

b

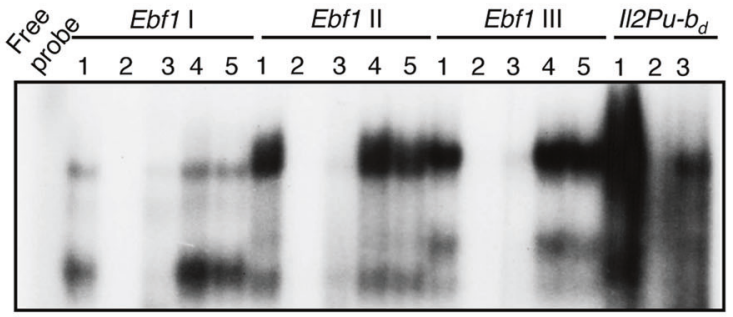

C

Chip: Chip:

input GST NFATC1

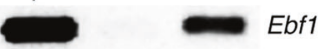

d

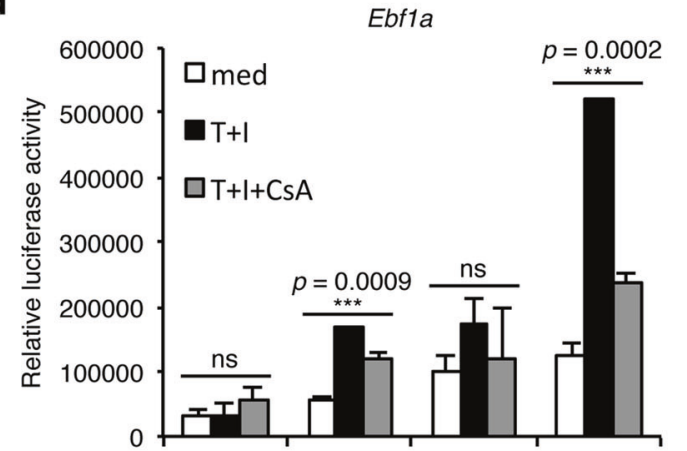

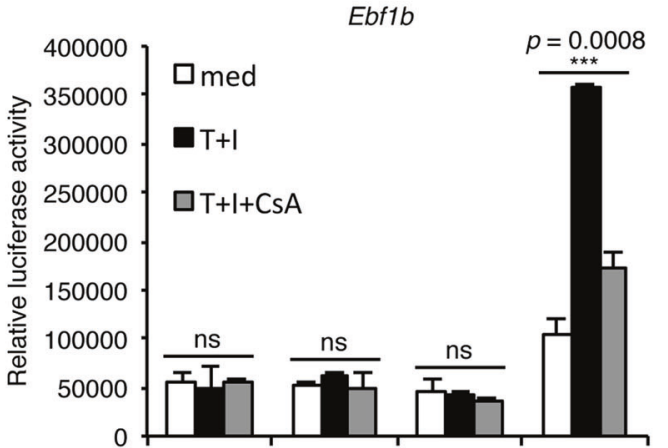

Fig. 5 NFATc1 binds the Ebf1 promoter and regulates its activity. a Conserved NFAT-binding consensus sequence (5'-GGAAA-3') in the Ebf1b promoter region 1-kb upstream of the transcriptional start site in mice and humans. b Electrophoretic mobility shift assay (EMSA) with nuclear extracts from BM pro-B cells showing NFATc1 binding at the conserved NFAT consensus sites in the Ebf1 promoter region. Ebf1 I, Ebf1 II, and Ebf1 III indicate the oligos used in EMSA containing the first, second, and third NFAT-binding sites. In each set, lane 1 represents NFAT-DNA complexes; lane 2, competition with 100-fold excess corresponding cold oligos; lane 3, supershift of NFAT-DNA complexes with NFATc1 Abs; lane 4, supershift of NFAT-DNA complexes with NFATc2 Abs; and lane 5, supershift of NFAT-DNA complexes with NFATc3 Abs. In the case of II2Pu box-distal (II2Pu- $\left.b_{d}\right)$, lanes 1-3 represent NFAT-DNA complexes, cold oligo competition, and supershift with NFATc1 Abs, respectively. c In vivo NFATc1 binding at the Ebf1 promoter as revealed in the ChIP assays. d Transactivation of Ebf1a and Ebf1b promoters in response to NFATC1 or STAT5 activity alone or both together as revealed by luciferase reporter assays. Data are representative of three independent experiments and are shown as the mean \pm s.d., one-way ANOVA (d)

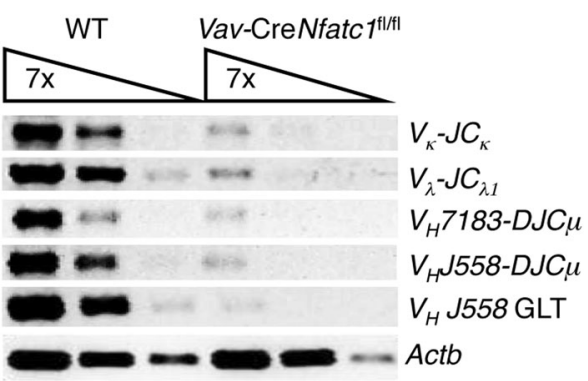

Fig. 6 NFATC1 deficiency impairs V-D-J recombination in VavCreNfatci ${ }^{\mathrm{f} / \mathrm{fl}}$ pro-B cells. RT-PCR analysis showing $\mathrm{V}-\mathrm{J}$ and $\mathrm{V}-\mathrm{D}-\mathrm{J}$ recombination at the light and heavy chain locus, respectively, in pro-B cells from Vav-CreNfatc ${ }^{\mathrm{fl} / \mathrm{fl}}$ mice compared with littermate control mice. Data are representative of two independent experiments with cDNA prepared from sorted cells collected from pooled $\mathrm{BM}$ cells from multiple mice for each genotype in each experiment in $\mathrm{Vav}$-CreNfatc1P2 $2^{\mathrm{fl} / \mathrm{fl}}$ mice was clearly due to compensation for the lost NFATC1 $\beta$ activity by the NFATc1a isoforms. These observations further underline the importance of NFATC1 in B cell development.

To gain insight concerning the absence of NFATc1a expression at the pro-B cell stage, when it is present in pre-B cells along with NFATC1 $\beta$ (Fig. $7 a$ ) and is able to replace NFATc1 $\beta$ activity during early $B$ cell development (Fig. 7f), we analyzed Vav-CreNfatclaA ${ }^{\mathrm{fl} / \mathrm{f}}$ mice in which a constitutively active version of NfatclaA was knocked-in in the Rosa-26 locus flanked by a floxed stop cassette. $^{34}$ Surprisingly, analysis of the spleen and BM revealed an NFATc1aA dose-dependent decrease in cellularity, suggesting a possible defect in $B$ cell development in Vav-CreNfatclaA ${ }^{\mathrm{fl} / \mathrm{f}}$ mice (Fig. 7g). Characterization of the $B$ cell populations revealed a drastic reduction of $\mathrm{B}_{2} 2 \mathrm{O}^{+}$cells in the $\mathrm{BM}$ and spleen (Fig. 7h and Supplementary Figure S4a). Furthermore, we observed a severe lack of $\operatorname{lgM}^{+}$and $\operatorname{lgD}^{+}$B cells in the BM and spleen, as well as follicular and marginal zone $B$ cells in the spleen of VavCreNfatc1aA $\mathrm{fl}^{\mathrm{f} / \mathrm{fl}}$ mice compared with their littermate controls (Fig. 7i, j and Supplementary Figure S4b and c). Additionally, the

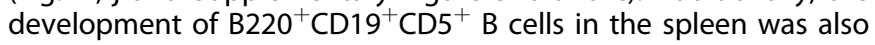


a

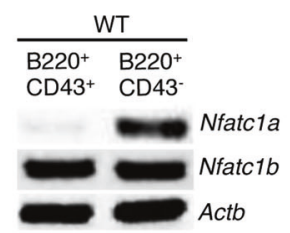

e
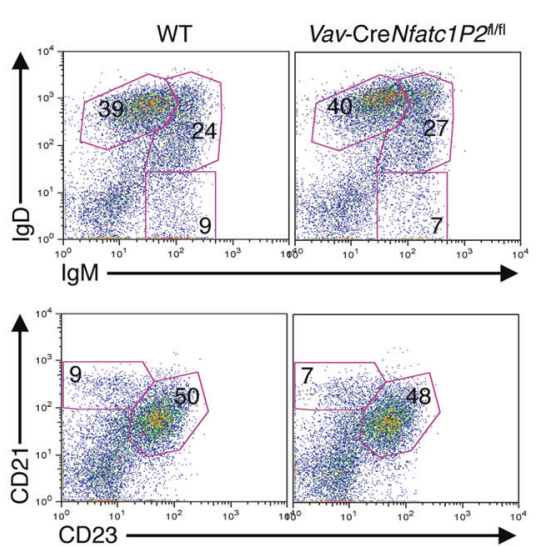

h

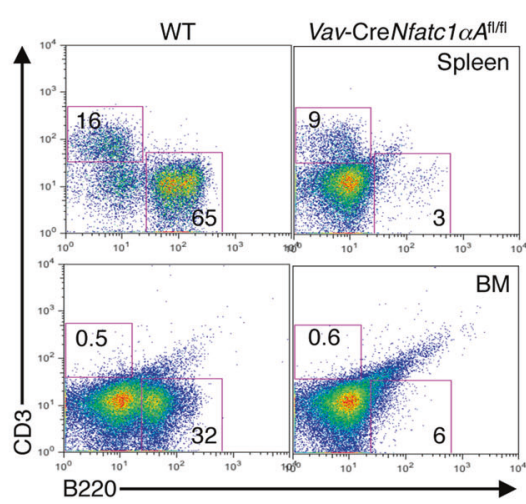

C

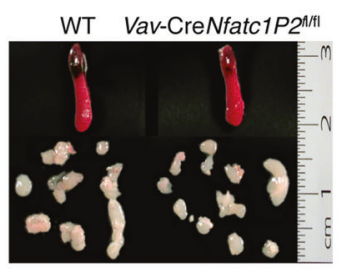

WT

- Vav-CreNfatc1P2itit
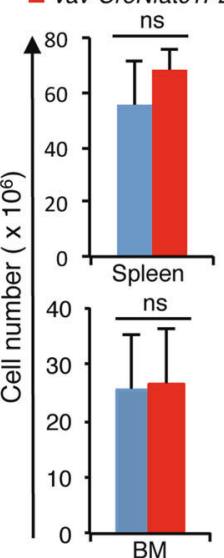

BM
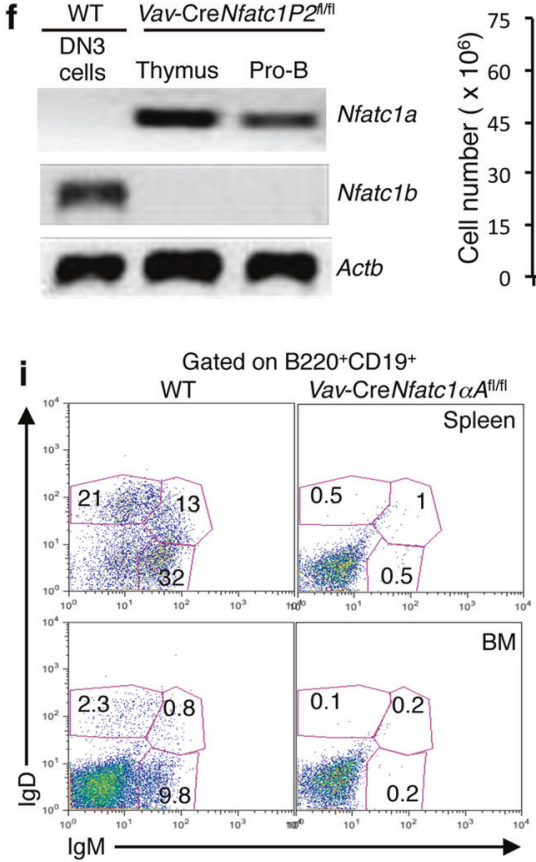

d

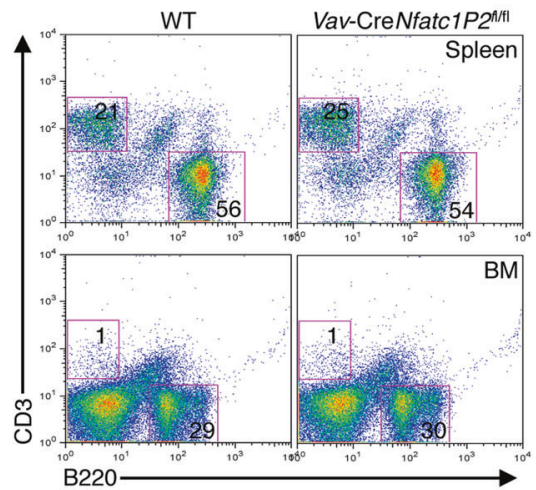

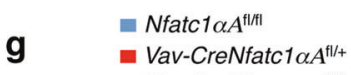

- Vav-CreNfatc1 $\alpha A^{\text {trft }}$
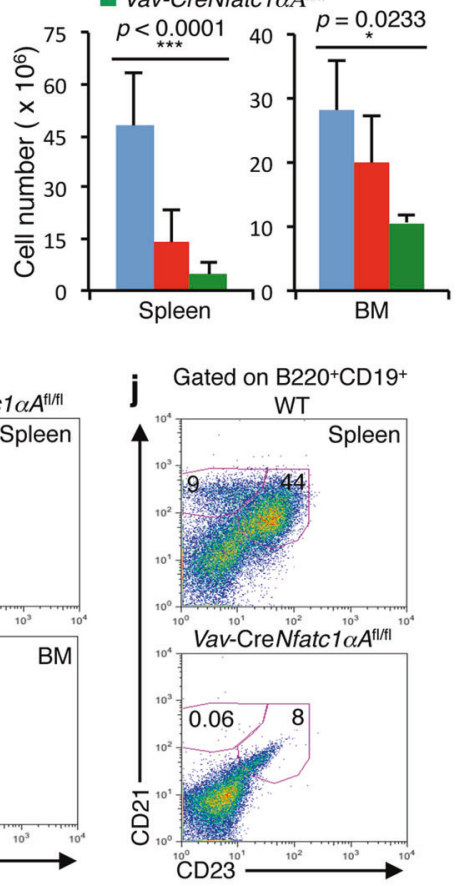

k
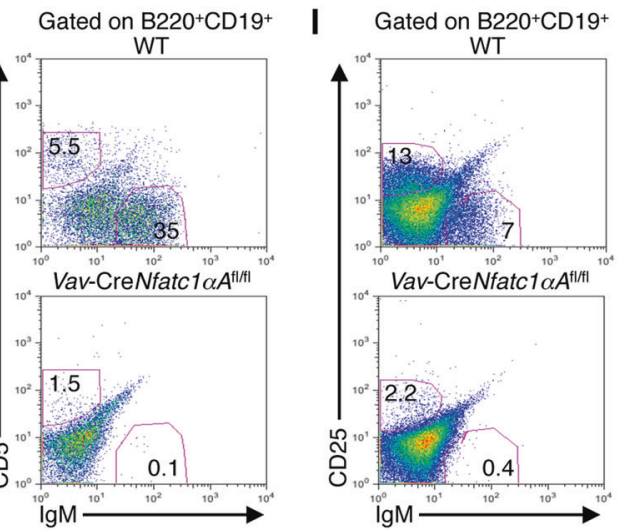

severely affected in Vav-CreNfatclaA ${ }^{\text {fl/fl }}$ mice (Fig. 7k and Supplementary Figure S4d). To locate the precise stage at which $B$ cell development was arrested as a result of NFATc1aA coexpression along with NFATC1 $\beta$, we analyzed the distribution of

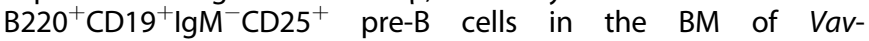

CreNfatc $1 \mathrm{aA} \mathrm{fl}^{\mathrm{fl} / \mathrm{fl}}$ mice. A drastically reduced pre-B cell population in the $B M$ revealed that, similar to the Vav-CreNfatc ${ }^{\text {fl/f }}$ mice, $B$ cell development in $\mathrm{Vav}$-CreNfatclaA $\mathrm{A}^{\mathrm{fl} / \mathrm{fl}}$ mice was blocked at the pro-B cell stage (Fig. $7 \mathrm{I}$ and Supplementary Figure S4e). These observations suggest that NFATc1a activity in addition to 
Fig. 7 Threshold level of NFATC1 activity is critical for B cell development. a Expression levels of Nfatc1a and Nfatc $1 b$ transcripts in $\mathrm{B} 22 \mathrm{O}^{+} \mathrm{CD} 43^{+}$pro-B and $\mathrm{B} 22 \mathrm{O}^{+} \mathrm{CD} 43^{-}$pre-B cells from WT mice. $\mathbf{b}$ Photographs of the spleen and LNs from Vav-CreNfatc1P2 ${ }^{\mathrm{fl} / \mathrm{fl}}$ mice compared with littermate control mice. c Cellularity in the spleen and BM from the indicated mice $\left(n=3\right.$ in each group). d CD3 ${ }^{+} \mathrm{T}_{\text {and }} \mathrm{B} 220^{+} \mathrm{B}$ cell distribution in the spleen and BM from Vav-CreNfatc $1 P 2^{f / 1 / 1}$ mice compared with WT control mice. e Splenic distribution of immature and mature (IgM vs IgD staining) and follicular and marginal zone (CD21 vs CD23 staining) B cells in WT and Vav-CreNfatc1P2 ${ }^{\mathrm{fl} / \mathrm{fl}}$ mice as revealed by flow cytometry. $\mathbf{f}$ Levels of Nfatc1a and Nfatc1b transcripts in WT DN3 (CD4 $\left.{ }^{-} \mathrm{CD} 8^{-} \mathrm{CD} 44^{-} \mathrm{CD} 25^{+}\right)$thymocytes and thymocytes and sorted pro-B cells from Vav-CreNfatc1P2 $2^{\mathrm{f} / \mathrm{fl}}$ mice. $\mathbf{g}$ Cellularity in the spleen and BM from Vav-CreNfatc1 $\alpha A^{\mathrm{fl} / \mathrm{fl}}$ mice $(n=12)$ compared with littermate Vav-CreNfatc $1 \alpha A^{\mathrm{fl} /+}(n=10)$ and WT mice $(n=9)$. $\mathbf{h}$ Flow cytometric profiles of the T and B cell distribution in the spleen and BM from VavCreNfatc $1 \alpha A^{\mathrm{fl} / \mathrm{fl}}$ mice compared with littermate control mice. $\mathbf{i}_{\mathrm{IgM}}{ }^{+}$and $\lg \mathrm{D}^{+} \mathrm{B}$ cell distribution in the spleen and $\mathrm{BM}$ of $\mathrm{Vav}-\mathrm{CreNfatc} 1 \alpha A^{\mathrm{fl} / \mathrm{fl}}$ and WT mice gated on the $\mathrm{B}_{2} 2 \mathrm{O}^{+} \mathrm{CD} 19^{+}$population. $\mathbf{j}$ Follicular and marginal zone $\mathrm{B}$ cell distribution in the spleen from the indicated mice

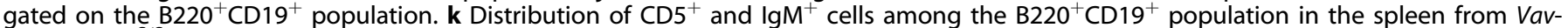

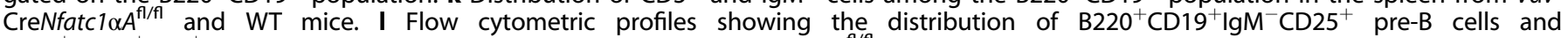
$\mathrm{B}_{22} 20^{+} \mathrm{CD} 19^{+} \mathrm{IgM}^{+} \mathrm{CD} 25^{-}$immature B cells in the BM from Vav-CreNfatc1 $\alpha A^{\mathrm{f} / \mathrm{fl}}$ mice compared with littermate control mice. Data represent one of the two (b) or three independent experiments ( $n=3-7$ per group) and are shown as the mean \pm s.d., paired $t$ test (c), ns not significant, and one-way ANOVA (g)

NFATc1 $\beta$ activity at the pro-B cell stage is detrimental for B cell development, and a certain threshold of NFATc1 activity irrespective of the $a$ or $\beta$ isoforms is indispensable for normal $B$ cell differentiation.

\section{DISCUSSION}

The role of NFAT proteins in early B cell developmental stages, during which they do not even have a pBCR, is not known. Our findings concerning NFAT protein expression in pro-B cells are quite intriguing (Fig. 1a-d and Supplementary Figure S1a and b). A previous report investigating the role of NFATC2 and NFATC3 in B cell development did not observe any abnormality in the BM, although the function of mature $B$ cells was affected. ${ }^{36}$ This phenomenon could be due to a functional compensation by NFATC1 in the absence of NFATC2 and NFATc3. Nfatc $1^{-1-}$ mice are embryonic lethal. ${ }^{48}$ Therefore, in an attempt to define the role of NFATC1 in B cells, we have previously used conditional mutant mice in which NFATc1 activity is ablated in a B cell-specific manner using Cd79a (Mb1, lga)-Cre transgenic mice $\left(M b 1-C r e N f a t c 1^{f / f l}\right){ }^{37}$ Although Iga is a component of the $\mathrm{pBCR}$ and is involved in $\mathrm{pBCR}$ signaling, analysis of $\mathrm{Mb} 1-\mathrm{CreNfatc} 1^{\mathrm{fl} / \mathrm{fl}}$ mice did not reveal any defects in early $B$ cell development. ${ }^{37}$ However, functional defects in mature $B$ cells were observed. These findings suggested that the absence of NFATc1 activity at a stage when B cells have already acquired the $\mathrm{pBCR}$ might not be appropriate to unravel its role in $\mathrm{PBCR}$-negative stages of differentiation. Accordingly, VavCre-mediated ablation of NFATC1 activity demonstrated the critical role played by NFATC1 in pro-B cell differentiation, which was not compensated by NFATC2 or NFATc3 (Figs. 2 and 3). The severe $B$ cell lymphopenia observed in the absence of NFATc1 activity (Fig. 2c, d) was not present in mice that were deficient in NFATC2, NFATc3, or both (Fig. 1e). These observations attribute a specific role to NFATc1, in contrast to the other NFAT family members, in regulating $B$ cell development in the $B M$.

Applying multiple approaches, we demonstrated the expression of NFATc1 in pBCR-negative pro-B cells (Fig. 1a-d, f Supplementary Figure S1a and b, and Fig. 7a). The functional significance of NFATc1 in these cells was clearly demonstrated by the B cell lymphopenia observed in Vav-CreNfatc $1^{\mathrm{f} / \mathrm{fl}}$ mice (Fig. 2c, d). In contrast to $\mathrm{pBCR}$ - or $\mathrm{BCR}$-bearing $\mathrm{B}$ cells, $\mathrm{pBCR}$-negative pro-B cells employ the alternative IL-7-Jak3-mediated mode to activate NFATC $1,{ }^{33}$ as evidenced in our kinase assays with immunoprecipitated JAK3 from pro-B cells (Fig. 1j, k). The role of NFATc1 in B-1 $B$ cell development has been previously reported. ${ }^{35}$ Our analysis of NFATc1 ablation at the earliest stages provides evidence that it is indispensable for the development of all types of B cells (Figs. 2 and 3 ).

The block at the pro-B cell stage in $\mathrm{Vav}$-CreNfatc $1^{\mathrm{f} / \mathrm{fl}}$ mice (Fig. $3 \mathrm{f}, \mathrm{g}$ ) was similar to that previously reported in $117^{-1-}$ and $1 / 7 r^{-1-}$ mice, suggesting that the interruption of IL-7-NFATc1 signaling might be the cause of this phenotype. EBF1 deficiency has been reported to be the main factor underlying the developmental arrest at the pro-B cell stage in $117^{-1-}$ and $117 r^{-1-}$ mice. ${ }^{47}$ Regulation of Ebf1 expression by IL-7 signaling has also been reported. ${ }^{16}$ However, the molecular mechanism linking IL-7 and Ebf1 expression is far from clear. Our observations regarding a strong defect in Ebf1 expression in pro-B cells from VavCreNfatc $7^{\mathrm{fl} / \mathrm{fl}}$ mice (Fig. 4a) suggested that, similar to $117^{-1-}$ and $1 / 7 r^{-1-}$ mice, the loss of EBF1 activity could be the major factor responsible for the impaired $B$ cell phenotype in these mice. Although we also observed downregulated Pax5 expression (Fig. 4a), it is not likely to be the reason for the observed phenotype because EBF1 has been shown to regulate Pax5 expression. ${ }^{16}$ Moreover, the strong downregulation in $\mathrm{pBCR}$ component expression (Cd79a, Cd79b, Vpreb, Igll1) and absence of Rag1, Rag2, and Tdt expression in Vav-CreNfatc ${ }^{\text {fl/f }}$ mice (Fig. 4a) resembled the phenotype of EBF1-deficient mice, in which $B$ cell development is also arrested at the pro-B cell stage. ${ }^{12}$ Interestingly, we observed an increase in the expression of Oct1, Oct2, Rela, Relb, Nfakb2, and Spi1 in Vav-CreNfatc $f^{\mathrm{f} / \mathrm{fl}}$ compared with littermate control mice (Fig. 4a); however, increased expression of these genes failed to rescue the B cell defects in Vav-CreNfatc $1^{\mathrm{fl} / \mathrm{fl}}$ mice. Additionally, the higher levels of $T c f 12, T c f 3$, and Id protein $\left(I d 1, I d 2\right.$, and Id3) expression in Vav-CreNfatc $1^{\mathrm{fl} / \mathrm{fl}}$ pro-B cells had no beneficial influence on B cell development (Fig. 4a). Overall, the gene expression defects in Vav-CreNfatc ${ }^{\text {fl/fl }}$ pro-B cells were similar to those observed in IL-7 signaling-deficient mice (Supplementary Figure S2b). Most interestingly, despite the block at the pro-B stage and the elevated expression levels of Notch proteins (Fig. 4a), no increases in T lineage cells were observed in Vav-CreNfatc $1^{\mathrm{f} / \mathrm{fl}}$ mice. Our analysis clearly demonstrates that the dysregulated Ebf1 expression in Vav-CreNfatc $1^{\text {fl/fl }}$ pro-B cells is the result of a lack of NFATC1 activity (Fig. 5). The defect in V-D-J recombination in Vav-CreNfatc $1^{\mathrm{fl} / \mathrm{fl}}$ pro-B cells (Fig. 6) again was similar to that reported in $117^{-1-}, 117 r^{-1-}$, and $\mathrm{Ebf1}^{-1-}$ mice. ${ }^{16,55} \mathrm{IL}-7$ signaling and EBF1 have been shown to regulate lg gene rearrangement. ${ }^{16,52,53}$ Again, the similarity in this aspect suggests that IL-7, NFATC1, and EBF1 all act in a linear axis (Supplementary Figure S5a) and that a deficiency in any one will lead to similar defects in B cell development.

In pro-B cells, Nfatc1 expression occurred exclusively from the P2 promoter, whereas in pre-B cells we could detect Nfatc1 expression from both the $\mathrm{P} 1$ and $\mathrm{P} 2$ promoters (Fig. 7a), marking a qualitative and quantitative difference in NFATc1 proteins in proand pre-B cells. This finding is again similar to our results obtained for pTCR-negative and pTCR-positive thymocytes during T cell development. ${ }^{33}$ In addition, this differential promoter-directed NFATc1 expression in pro- and pre-B cells reflects the threshold of NFATC1 activity required for their differentiation, as evidenced in our analysis of Vav-CreNfatc1P2 ${ }^{\mathrm{fl} / \mathrm{fl}}$ mice, where in the absence of $\mathrm{P} 2$, P1 promoter activity compensated for the loss of NFATc1 $\beta$ and 
facilitated normal B cell development (Fig. 7d, e and Supplementary Figure S3). Additionally and stressing the importance of a threshold level of NFATC1 activity during a stage-specific differentiation of B cells, increased NFATC1 levels via the coexpression of NFATc1a along with NFATC1 $\beta$ in pro-B cells led to severe B cell lymphopenia (Fig. $7 \mathrm{~g}-\mathrm{I}$ and Supplementary Figure S4).

In summary, our study underlines the essentiality of an optimal level of NFATC1 activity for B cell development and for preventing B cell lymphopenia (Supplementary Figure S5b). Our study also raises the possibility of manipulating NFATC1 activity to provide relief in clinical cases of B cell immunodeficiency.

\section{ACKNOWLEDGEMENTS}

The authors thank C. Linden and E. Schmitt (University of Würzburg) for excellent cell sorting and photographs of mouse organs, respectively, V. Ellenrieder (University of Goettingen) for the NfatclaA $A^{\mathrm{f} / \mathrm{fl}}$ mice, and A. Rao (University of California at San Diego) and L. Glimcher (Harvard Medical School and Brigham and Women's Hospital) for the $\mathrm{Nfatcl}^{\mathrm{fl} / \mathrm{fl}}$ mice. This work was supported by a Deutsche José Carreras Leukämie-Stiftung e.V. grant (DJCLS R 15/12) (to A.K.P.), a fellowship from the Vandervell Foundation, UK (to A.K.P.), Deutsche Forschungsgemeinschaft (DFG) grant TRR52 (to E.S.) and by the Wilhelm Sander-Stiftung (to E.S. and S.K.-H.).

\section{ADDITIONAL INFORMATION}

The online version of this article (https://doi.org/10.1038/s41423-018-0052-9) contains supplementary material.

Competing interests: The authors declare no competing interests.

Publisher's note: Springer Nature remains neutral with regard to jurisdictional claims in published maps and institutional affiliations.

\section{REFERENCES}

1. Sudo, T. et al. Expression and function of the interleukin 7 receptor in murine lymphocytes. Proc. Natl. Acad. Sci. USA 90, 9125-9129 (1993).

2. Grabstein, K. H. et al. Inhibition of murine B and T lymphopoiesis in vivo by an anti-interleukin 7 monoclonal antibody. J. Exp. Med. 178, 257-264 (1993).

3. Peschon, J. J. et al. Early lymphocyte expansion is severely impaired in interleukin 7 receptor-deficient mice. J. Exp. Med. 180, 1955-1960 (1994).

4. von Freeden-Jeffry, U. et al. Lymphopenia in interleukin (IL)-7 gene-deleted mice identifies IL-7 as a nonredundant cytokine. J. Exp. Med. 181, 1519-1526 (1995).

5. Miller, J. P. et al. The earliest step in B lineage differentiation from common lymphoid progenitors is critically dependent upon interleukin 7. J. Exp. Med. 196, 705-711 (2002)

6. Clark, M. R., Cooper, A. B., Wang, L. D. \& Aifantis, I. The pre-B cell receptor in B cell development: recent advances, persistent questions and conserved mechanisms. Curr. Top. Microbiol. Immunol. 290, 87-103 (2005).

7. Herzog, S., Reth, M. \& Jumaa, H. Regulation of B-cell proliferation and differentiation by pre-B-cell receptor signalling. Nat. Rev. Immunol. 9, 195-205 (2009).

8. Hagman, J. \& Lukin, K. Transcription factors drive B cell development. Curr. Opin. Immunol. 18, 127-134 (2006).

9. Nutt, S. L. \& Kee, B. L. The transcriptional regulation of B cell lineage commitment. Immunity 26, 715-725 (2007)

10. Bain, G. et al. E2A proteins are required for proper B cell development and initiation of immunoglobulin gene rearrangements. Cell 79, 885-892 (1994).

11. Bain, G. et al. Both E12 and E47 allow commitment to the B cell lineage. Immunity 6, 145-154 (1997).

12. Lin, H. \& Grosschedl, R. Failure of B-cell differentiation in mice lacking the transcription factor EBF. Nature 376, 263-267 (1995).

13. Zhang, Z., Cotta, C. V., Stephan, R. P., deGuzman, C. G. \& Klug, C. A. Enforced expression of EBF in hematopoietic stem cells restricts lymphopoiesis to the $B$ cell lineage. EMBO J. 22, 4759-4769 (2003).

14. Nutt, S. L., Urbanek, P., Rolink, A. \& Busslinger, M. Essential functions of Pax5 (BSAP) in pro-B cell development: difference between fetal and adult B lymphopoiesis and reduced V-to-DJ recombination at the IgH locus. Genes Dev. 11, 476-491 (1997)

15. Nutt, S. L., Heavey, B., Rolink, A. G. \& Busslinger, M. Commitment to the Blymphoid lineage depends on the transcription factor Pax5. Nature 401, 556-562 (1999).
16. Hagman, J., Ramirez, J. \& Lukin, K. B lymphocyte lineage specification, commitment and epigenetic control of transcription by early B cell factor 1. Curr. Top. Microbiol. Immunol. 356, 17-38 (2012).

17. Gyory, I. et al. Transcription factor Ebf1 regulates differentiation stage-specific signaling, proliferation, and survival of B cells. Genes Dev. 26, 668-682 (2012).

18. O'Riordan, M. \& Grosschedl, R. Coordinate regulation of B cell differentiation by the transcription factors EBF and E2A. Immunity 11, 21-31 (1999).

19. Kim, U. et al. The B-cell-specific transcription coactivator OCA-B/OBF-1/Bob-1 is essential for normal production of immunoglobulin isotypes. Nature $\mathbf{3 8 3}$, 542-547 (1996).

20. Schubart, D. B., Rolink, A., Kosco-Vilbois, M. H., Botteri, F. \& Matthias, P. B-cellspecific coactivator OBF-1/OCA-B/Bob1 required for immune response and germinal centre formation. Nature 383, 538-542 (1996).

21. Dengler, H. S. et al. Distinct functions for the transcription factor Foxo1 at various stages of B cell differentiation. Nat. Immunol. 9, 1388-1398 (2008).

22. Maier, H. et al. Early B cell factor cooperates with Runx 1 and mediates epigenetic changes associated with mb-1 transcription. Nat. Immunol. 5, 1069-1077 (2004).

23. Lukin, K. et al. Compound haploinsufficiencies of Ebf1 and Runx 1 genes impede $B$ cell lineage progression. Proc. Natl. Acad. Sci. USA 107, 7869-7874 (2010).

24. Kikuchi, K., Lai, A. Y., Hsu, C. L. \& Kondo, M. IL-7 receptor signaling is necessary for stage transition in adult $\mathrm{B}$ cell development through up-regulation of EBF. J. Exp. Med. 201, 1197-1203 (2005).

25. Kee, B. L. \& Murre, C. Induction of early B cell factor (EBF) and multiple B lineage genes by the basic helix-loop-helix transcription factor E12. J. Exp. Med. 188, 699-713 (1998).

26. Smith, E. M., Gisler, R. \& Sigvardsson, M. Cloning and characterization of a promoter flanking the early $B$ cell factor (EBF) gene indicates roles for E-proteins and autoregulation in the control of EBF expression. J. Immunol. 169, 261-270 (2002).

27. Lin, Y. C. et al. A global network of transcription factors, involving E2A, EBF1 and Foxo1, that orchestrates B cell fate. Nat. Immunol. 11, 635-643 (2010).

28. Rao, A., Luo, C. \& Hogan, P. G. Transcription factors of the NFAT family: regulation and function. Annu. Rev. Immunol. 15, 707-747 (1997).

29. Crabtree, G. R. \& Olson, E. N. NFAT signaling: choreographing the social lives of cells. Cell 109, Suppl:S67-Suppl:S79 (2002).

30. Hogan, P. G., Chen, L., Nardone, J. \& Rao, A. Transcriptional regulation by calcium calcineurin, and NFAT. Genes Dev. 17, 2205-2232 (2003).

31. Macian, F. NFAT proteins: key regulators of T-cell development and function. Nat. Rev. Immunol. 5, 472-484 (2005).

32. Serfling, E. et al. NFAT transcription factors in control of peripheral T cell tolerance. Eur. J. Immunol. 36, 2837-2843 (2006).

33. Patra, A. K. et al. An alternative NFAT-activation pathway mediated by IL-7 is critical for early thymocyte development. Nat. Immunol. 14, 127-135 (2013).

34. Klein-Hessling, S. et al. A threshold level of NFATc1 activity facilitates thymocyte differentiation and opposes notch-driven leukaemia development. Nat. Commun. 7, 11841 (2016).

35. Berland, R. \& Wortis, H. H. Normal B-1a cell development requires B cell-intrinsic NFATc1 activity. Proc. Natl. Acad. Sci. USA 100, 13459-13464 (2003).

36. Samanta, D. N. et al. B cell hyperresponsiveness and expansion of mature follicular B cells but not of marginal zone B cells in NFATc2/c3 double-deficient mice. J. Immunol. 174, 4797-4802 (2005).

37. Bhattacharyya, S. et al. NFATc1 affects mouse splenic B cell function by controlling the calcineurin-NFAT signaling network. J. Exp. Med. 208, 823-839 (2011).

38. Peng, S. L., Gerth, A. J., Ranger, A. M. \& Glimcher, L. H. NFATc1 and NFATc2 together control both $\mathrm{T}$ and $\mathrm{B}$ cell activation and differentiation. Immunity 14, 13-20 (2001).

39. Patra, A. K. et al. PKB rescues calcineurin/NFAT-induced arrest of Rag expression and pre-T cell differentiation. J. Immunol. 177, 4567-4576 (2006).

40. Patra, A. K., Na, S. Y. \& Bommhardt, U. Active protein kinase B regulates TCR responsiveness by modulating cytoplasmic-nuclear localization of NFAT and NFkappa B proteins. J. Immunol. 172, 4812-4820 (2004).

41. Fuxa, M. et al. Pax 5 induces V-to-DJ rearrangements and locus contraction of the immunoglobulin heavy-chain gene. Genes Dev. 18, 411-422 (2004).

42. Roessler, S. et al. Distinct promoters mediate the regulation of Ebf1 gene expression by interleukin-7 and Pax5. Mol. Cell. Biol. 27, 579-594 (2007).

43. Hock, M. et al. NFATC1 induction in peripheral T and B lymphocytes. J. Immunol. 190, 2345-2353 (2013).

44. Bueno, O. F., Brandt, E. B., Rothenberg, M. E. \& Molkentin, J. D. Defective T cell development and function in calcineurin A beta -deficient mice. Proc. Natl. Acad. Sci. USA 99, 9398-9403 (2002).

45. Winslow, M. M., Gallo, E. M., Neilson, J. R. \& Crabtree, G. R. The calcineurin phosphatase complex modulates immunogenic B cell responses. Immunity $\mathbf{2 4}$ 141-152 (2006). 
46. Corcoran, A. E. et al. The interleukin-7 receptor alpha chain transmits distinct signals for proliferation and differentiation during B lymphopoiesis. EMBO J. 15, 1924-1932 (1996).

47. Milne, C. D. \& Paige, C. J. IL-7: a key regulator of B lymphopoiesis. Semin. Immunol. 18, 20-30 (2006).

48. de la Pompa, J. L. et al. Role of the NF-ATc transcription factor in morphogenesis of cardiac valves and septum. Nature 392, 182-186 (1998).

49. Hardy, R. R., Carmack, C. E., Shinton, S. A., Kemp, J. D. \& Hayakawa, K. Resolution and characterization of pro-B and pre-pro-B cell stages in normal mouse bone marrow. J. Exp. Med. 173, 1213-1225 (1991).

50. Gerondakis, S. \& Siebenlist, U. Roles of the NF-kappaB pathway in lymphocyte development and function. Cold Spring Harb. Perspect. Biol. 2, a000182 (2010).

51. Almaden, J. V. et al. B-cell survival and development controlled by the coordination of NF-kappaB family members RelB and cRel. Blood 127, 1276-1286 (2016).

52. Corcoran, A. E., Riddell, A., Krooshoop, D. \& Venkitaraman, A. R. Impaired immunoglobulin gene rearrangement in mice lacking the IL-7 receptor. Nature 391, 904-907 (1998).

53. Chowdhury, D. \& Sen, R. Stepwise activation of the immunoglobulin mu heavy chain gene locus. EMBO J. 20, 6394-6403 (2001).
54. Chuvpilo, S. et al. Autoregulation of NFATc1/A expression facilitates effector T cells to escape from rapid apoptosis. Immunity 16, 881-895 (2002).

55. Corfe, S. A. \& Paige, C. J. The many roles of IL-7 in B cell development; mediator of survival, proliferation and differentiation. Semin. Immunol. 24, 198-208 (2012).

Open Access This article is licensed under a Creative Commons Attribution 4.0 International License, which permits use, sharing, adaptation, distribution and reproduction in any medium or format, as long as you give appropriate credit to the original author(s) and the source, provide a link to the Creative Commons license, and indicate if changes were made. The images or other third party material in this article are included in the article's Creative Commons license, unless indicated otherwise in a credit line to the material. If material is not included in the article's Creative Commons license and your intended use is not permitted by statutory regulation or exceeds the permitted use, you will need to obtain permission directly from the copyright holder. To view a copy of this license, visit http://creativecommons. org/licenses/by/4.0/.

(c) The Author(s) 2018 